\title{
FLEXIBILIDAD \\ CURRICULAR EN LA \\ EDUCACIÓN BIBLIOTECOLÓGICA
}

COORDINADORA

Lina Escalona Ríos

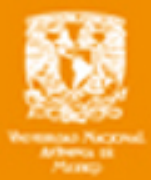

CUADERNOS DE INVESTIGACION 7 
La presente obra está bajo una licencia de:

http://creativecommons.org/licenses/by-ncsa/3.0/deed.es MX

\section{(c) cointive}

Eres libre de:

(15)

copiar, distribuir y comunicar públicamente la obra

(D) hacer obras derivadas

Bajo las condiciones siguientes:

Atribución - Debes reconocer la autoría de la obra en los términos

especificados por el propio autor o licenciante.

No comercial - No puedes utilizar esta obra para fines comerciales.

Licenciamiento Reciproco - Si alteras, transformas o creas una obra a

partir de esta obra, solo podrás distribuir la obra resultante bajo una licencia igual a ésta.

Esto es un resumen fácilmente legible del: texto legal (de la licencia completa)

\section{En los casos que sea usada la presente obra, deben respetarse los términos especificados en esta licencia.}
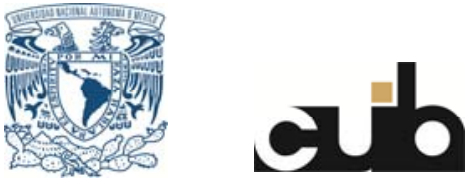
Flexibilidad curricular en la educación bibliotecológica 
COLECCIÓN

Cuadernos de Investigación 7

Centro Universitario de Investigaciones Bibliotecológicas 


\title{
Flexibilidad curricular en la educación bibliotecológica
}

\author{
Coordinadora \\ Lina Escalona Ríos
}

Colaboradores

Sueli Angelica do Amaral

Rosa Elba Chacón Escobar

Rosa María Martínez Rider

María Teresa Múnera Torres

Universidad Nacional Autónoma de México 2008 
Z669.5

A5F5 Flexibilidad curricular en la educación bibliotecológica/coordinadora, Lina Escalona Ríos ; participantes, Sueli Angelica do Amaral... [et al.] .—México : UnAM, Centro Universitario de Investigaciones Bibliotecológicas, 2008.

x, 115 p. - (Cuadernos de Investigación ; 7)

ISBN: 978-607-02-0769-3

El presente documento es el resultado del primer foro de discusión del Seminario Permanente de Educación Bibliotecológica.

1. Educación Bibliotecológica - Iberoamérica 2. Bibliotecología-Currículos 3. Escuelas de Bibliotecología Currículos 4. Educación bibliotecológica - Flexibilidad Curricular I. Escalona Ríos, Lina, coordinadora. II. Amaral, Sueli Angélica do III. ser.

\section{Diseño de portada: Mario Ocampo Chávez}

Primera Edición, 2008

DR (C) UNIVERSIDAD NACIONAL AUTÓNOMA DE MÉXICO

Ciudad Universitaria, 04510, México, D.F.

Impreso y hecho en México

ISBN: 978-607-02-0769-3 


\section{Contenido}

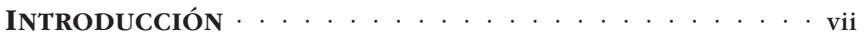

LA EDUCACIÓN BIBLIOTECOLÓGICA EN

IBEROAMÉRICA

Lina Escalona Ríos . . . . . . . . . . . . . . . . . . . . . 1

MÉTODO DE ENSINO E APRENDIZAGEM PARA

O DESENVOLVIMENTO HUMANO INTEGRADO

DO PROFISSIONAL DA INFORMAÇÃO

Sueli Angélica do Amaral . . . . . . . . . . . . . . . 25

CURRículo Formal de BIBLIOTECOLOGÍA EN LA

UNIVERSIDAD AUTÓNOMA DE CHIAPAS,

FACUlTAd DE HuMANidAdes CAMPUS VI

Rosa Elba Chacón Escobar

LA FLEXIBILIDAD CURRICULAR Y LA HOMOLOGACIÓN DE PLANES DE ESTUdIO

Rosa María Martínez Rider . . . . . . . . . . . . . . . 65

LA FORMACIÓN DEL PROFESIONAL DE LA INFORMACIÓN

EN LA ESCUELA INTERAMERICANA DE

Bibliotecología

María Teresa Múnera Torres . . . . . . . . . . . . . . . . 75

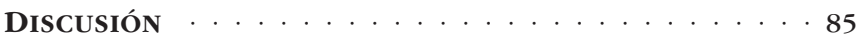

CONCLUSIONES $\ldots \ldots \ldots \ldots \ldots \ldots$ 


\section{Introducción}

Taciendo uso de las ventajas que las Tecnolo1 gías de la Información y la Comunicación actualmente ofrecen, el Centro Universitario de Investigaciones Bibliotecológicas ha auspiciado, desde 2006, los trabajos del Seminario Virtual sobre Educación Bibliotecológica. El objetivo principal que persigue este Seminario es analizar y discutir los problemas y fenómenos que tienen relación directa con la educación bibliotecológica. A través de la comunicación en forma virtual, los investigadores y profesores de Iberoamérica interesados en esta temática, hemos analizado y discutido en el Foro electrónico, desarrollado por el CUIB para este Seminario, diversos aspectos de interés regional sobre esta temática.

En ese contexto, los miembros del Seminario Virtual sobre Educación Bibliotecológica, investigadores y profesores de México, Brasil, Colombia, 
Flexibilidad curricular en la educación bibliotecológica

Costa Rica, España, Perú y Venezuela, nos propusimos la discusión, dentro del Foro electrónico, de un tema de suma relevancia para la educación bibliotecológica: la flexibilidad curricular. Aspecto que en una sociedad global en la que el desarrollo científico avanza día a día, junto con el tecnológico $\mathrm{y}$ de telecomunicaciones, se vuelve fundamental para el diseño curricular en nuestra disciplina, si pensamos en la formación profesional a futuro.

Con la finalidad de conocer los puntos de vista de especialistas de diferentes países, se consideró adecuado contar con varios documentos como base para llevar a cabo la discusión, por lo que se solicitó a cuatro miembros del Seminario que elaboraran un documento sobre la flexibilidad curricular en la educación bibliotecológica. De esta forma, como punto de partida se contó con los documentos elaborados por Lina Escalona Ríos (Centro Universitario de Investigaciones Bibliotecológicas), Sueli Angélica do Amaral (Departamento de Ciência de la Informação y Documentação da Universidade de Brasília) Rosa Elba Chacón Escobar (Facultad de Humanidades, Universidad Autónoma de Chiapas), Rosa María Martínez Rider (Escuela de Bibliotecología e Información, Universidad Autónoma de San Luis Potosí) y María Teresa Múnera López (Escuela Interamericana de Bibliotecología, Universidad de Antioquia, Colombia). 
Asimismo, se solicitó a los miembros del Seminario que para la discusión tuviesen presentes los conceptos de reconocidos especialistas en Pedagogía expresados en los siguientes artículos: "Propuesta de un modelo curricular flexible para mejorar la calidad de la formación profesional "de René Pedroza Flores y "Flexibilidad curricular: mayor equidad en el acceso y permanencia en la educación superior" de María del Rosario Guerra, Nohra Pabón y José Manuel Restrepo.

Tomando en cuenta lo anterior y los documentos elaborados para la discusión, los diversos miembros del Seminario vertieron sus opiniones sobre este tema durante una semana. Participaron en las discusiones efectuadas dentro del Foro electrónico, los siguientes miembros del Seminario: Juan Alva Leonel (Ciudad de México), Magdaleno Azotla Álvarez (Ciudad de México), Elsa Barber (Argentina), Brenda Cabral Vargas (Ciudad de México), Rosa Elba Chacón Escobar (Chiapas, México), Lina Escalona Ríos (Ciudad de México), Rocío Gómez Sustaita (Guadalajara, Jalisco, México), Juan Carlos Marcos Recio (España), Rosa María Martínez Rider (San Luis Potosí, México), Isabel Miranda Meruvia (Perú), María Elvia Vázquez Velásquez (Ciudad de México), Alice Miranda Arguedas (Costa Rica), Sueli Angelica do Amaral (Brasil), Elba 
Flexibilidad curricular en la educación bibliotecológica

Fernández Cruz (Ciudad de México) y María Teresa Múnera Torres (Colombia).

Considerando que los documentos que sirvieron como punto de partida para la discusión sobre esta temática, así como el contenido de la misma, podrían ser de utilidad para los investigadores y profesores interesados en ella, se consideró conveniente su publicación en la serie Cuadernos de Investigación del Centro Universitario de Investigaciones Bibliotecológicas. Es de esperarse que para la comunidad bibliotecológica interesada en esta temáti$\mathrm{ca}$, la presente publicación sirva de punto de parti$\mathrm{da}$ para efectuar investigaciones de mayor profundidad. Asimismo, agradezco la participación de todos aquellos miembros del Seminario Virtual sobre Educación Bibliotecológica que hicieron posible la realización de esta discusión académica y los invito a seguir participando con su valioso conocimiento y experiencia profesional.

Lina Escalona Ríos 


\title{
La educación bibliotecológica en Iberoamérica
}

\author{
LINA ESCALONA RÍOS
}

\section{Introducción}

G n el siglo XXI la educación bibliotecológica en- frenta una serie de retos que se tienen que valorar para saber cómo enfrentarlos y hacer realidad lo que se espera del bibliotecólogo en la sociedad del conocimiento.

La globalización económica está afectando a las profesiones y a los profesionales que se enfrentan a un mercado común al que tienen que atender con la misma calidad y con una amplitud de conocimientos comunes, que los lleven a mostrar su competitividad en el ámbito internacional. Pero esta idea que teóricamente es correcta o ideal, en el contexto actual de la formación profesional de bibliotecólogos 
Flexibilidad curricular en la educación bibliotecológica

en Iberoamérica, enfrenta tal serie de discrepancias y diversidad de profesionales que dieron lugar a este documento. Así, el objetivo de este trabajo es presentar las características generales de los planes de estudio que están formando a los profesionales del área bibliotecológica en Iberoamérica. Para hacer el análisis se eligieron, de forma aleatoria, dos escuelas de cada país; excepto el caso de Bolivia porque sólo hay una y el de México porque ya se cuenta con un estudio sobre todas las instituciones.

Para efectos de la discusión del Foro Académico del Seminario de Educación Bibliotecológica, las tendencias de la educación bibliotecológica se abordarán desde los siguientes aspectos:

- Títulos que proporcionan las instituciones educativas

- Tiempo de duración de los estudios

- Tipo de currículo

- Tendencia disciplinar

- Imagen del profesional en el perfil

- Campo de trabajo

Lo anterior permitirá generar la discusión sobre un punto básico que debe considerarse en el entorno de la calidad, la globalización y la internacionalización de la educación superior: la flexibilidad curricular. 


\section{Antecedentes}

En 1996, Emilio Setién presentó el documento "Tendencias de la formación bibliotecológica en la América Latina" en el 3er Encuentro de Educadores e Investigadores de Bibliotecología, Archivología y Ciencia de la Información de Iberoamérica y el Caribe; dicho documento analizaba 20 planes de estudio y establecía que

[... ]algunas Universidades han concebido planes que permitan formar en pregrado a un profesional capaz de ejercer sus funciones potencialmente tanto en las instituciones bibliológico informativas tradicionales (archivos, bibliotecas, centros de información y documentación) como en nuevos puestos de trabajo que se perfilan hoy en el mercado laboral de la información (Setién, 1996).

Setién menciona también las siguientes características:

- Ausencia de contenidos relacionados con la bibiografología, archivología y ciencia de la información como la generación de datos e información, consultoría, diagnósticos, promoción de la lectura, etcétera.

- Existe variedad en la denominación y niveles de los títulos que se otorgan.

- Hay también diversidad en el tiempo de duración de los estudios. 
Flexibilidad curricular en la educación bibliotecológica

- Son generales las licenciaturas de cuatro años para la bibliotecología.

En cuanto al mercado laboral, éste varía de un país a otro y de una escuela a otra, por lo que los estudiantes salen con formación diversa, sostiene Setién, debido a que las instituciones queriendo adecuarse a las exigencias del mercado crean una confusión entre la formación general que ofrecen las instituciones educativas y los requerimientos del mercado.

En la misma línea, el trabajo realizado por Johann Pirela (2005) expone las tendencias y perspectivas para la enseñanza de la bibliotecología en la cibersociedad; el autor parte de las tendencias que establece la UNESCO para el currículo del siglo XXI y las sintetiza de la forma siguiente:

1. El currículo es la concreción de una teoría pedagógica y un plan en permanente construcción.

2. La formación profesional debe basarse en competencias.

3. La pertinencia y la calidad serán principios orientadores del currículo.

4. La adopción de nuevos modelos pedagógicos estarán centrados en el "aprender a aprender" y en el desarrollo de procesos del pensamiento.

5. La introducción de las tecnologías de información y comunicación será un como eje transver- 
sal y una nueva forma de conducir los procesos de aprendizaje.

6. La investigación y la transdiciplinariedad serán vía para abordar la complejidad del currículo. (Pirela, 2005).

Analizando dos escuelas, una de México y otra de Venezuela, Johann Pirela llega a las siguientes consideraciones que son de relevancia para efectos del presente trabajo:

- La mayor parte de las Escuelas introduce concepciones curriculares de tipo academicista; sólo una de las escuelas estudiadas expresa estar enmarcada en la concepción constructivista.

- Las escuelas no incorporan el enfoque de competencias en sus planes de estudio.

- Aunque en México se ha hecho un estudio de mercado reciente (Escalona, 2005), sus resultados no se han incorporado en los planes de estudio como elementos de sustentación empírica y de pertinencia social.

- Los planes de estudio han introducido las tecnologías de información y comunicación como ejes de conocimiento, pero no como eje transversal ni como recursos de apoyo a la práctica docente.

- Se propone la realización de encuentros académicos para avanzar hacia procesos de compatibilización curricular de los planes de estudio en Biblio- 
Flexibilidad curricular en la educación bibliotecológica

tecología y Archivología de países de América Latina como México y Venezuela (Pirela, 2005).

Otro estudio considerado es el de Escalona (2005) que menciona las tendencias curriculares de cinco escuelas de México y vincula estas tendencias con el mercado de trabajo en el que se desenvuelven los profesionales, encontrando que hay discrepancias entre el tipo de profesional que se forma y las actividades profesionales que realiza. Veamos:

Figura 1

Correspondencia entre los perfiles profesionales, la tendencia de las asignaturas y las actividades profesionales

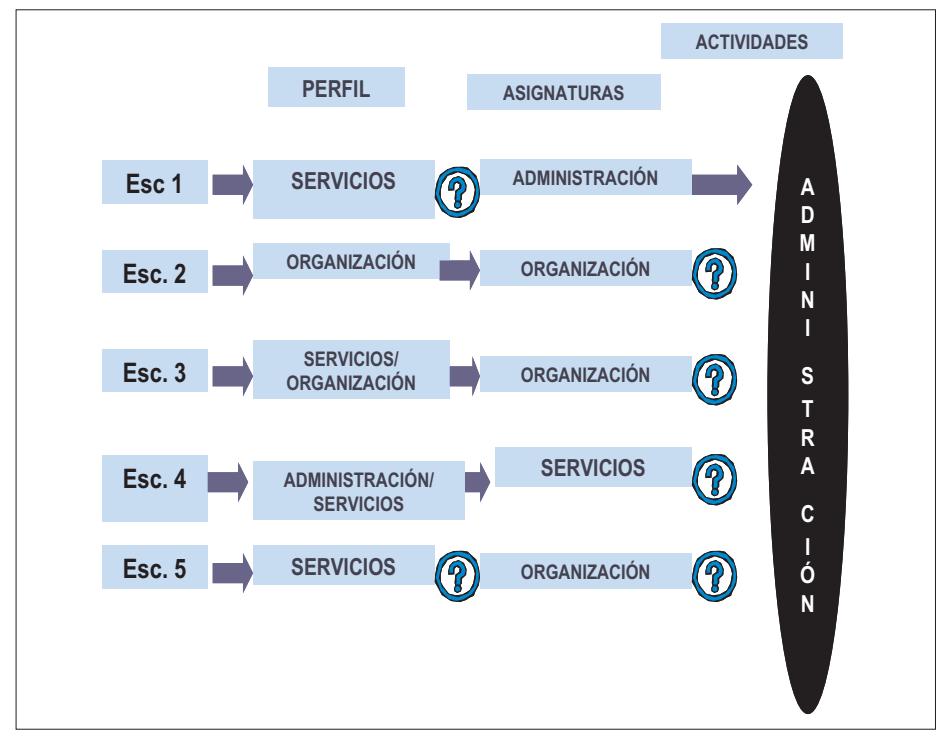

NOTA: Los signos de interrogación indican la falta de correspondencia entre el perfil, las asignaturas y/o las actividades. 
Es decir, hace falta alcanzar mayor congruencia entre el perfil que la institución propone y la tendencia en las asignaturas, ya que la mayoría de los profesionales se encuentra realizando actividades de orden administrativo y gestión de bibliotecas y servicios.

\section{Entorno de la educación bibliotecológica iberoamericana actual}

En Iberoamérica la educación bibliotecológica ha tenido que enfrentar una serie de retos que ha debido asumir cada institución educativa de forma particular. El fenómeno de la globalización, especialmente, le ha dado una nueva dimensión a la educación superior en Europa y Estados Unidos de Norteamérica, donde se tiene mejor definido el tipo de profesional que requiere una sociedad globalizada.

Se entiende que "[... ]la globalización es un fenómeno cualitativamente nuevo que se hace posible a partir de la coincidencia en el tiempo de tres procesos interdependientes con su propia lógica interna: la crisis y derrumbe del socialismo real, el desarrollo vertiginoso de las nuevas tecnologías de la información y de la comunicación (era de la información) y el neoliberalismo [... ] Su nacimiento puede situarse a inicios de los 90 y hace posible por vez primera que los empresarios transnacionales de- 
Flexibilidad curricular en la educación bibliotecológica

sempeñen un papel clave, no sólo en el manejo de la economía, sino de la sociedad en su conjunto" (López Segrera, p. 37). Esta globalización ha afectado a la educación bibliotecológica, fundamentalmente en dos áreas:

A nivel externo, en el mercado de trabajo, la forma en que se desarrollan las actividades, profesionales y no profesionales del bibliotecólogo han cambiado y han surgido nuevas actividades para las que el bibliotecario "tradicional" no estaba preparado, por ejemplo el diseño y la venta de servicios de información o la incursión en los sistemas de información digitales y/o virtuales.

Por otra parte se tiende a exigir cada vez más la rendición de cuentas en el área laboral con relación al manejo de los recursos y los resultados alcanzados respecto a objetivos predefinidos. La cultura de la evaluación de nuestras actividades no es una actividad aceptada positivamente a nivel general.

A nivel interno, el currículo se torna cada vez más complejo ya que se debe formar a los estudiantes para enfrentar los retos de la sociedad globalizada, por lo que además de los conocimientos teórico prácticos disciplinarios, también se les debe enseñar el manejo de las nuevas tecnologías aplicadas a sus actividades y deben manejar varios idiomas, de modo que puedan demostrar su competitividad a 
nivel nacional e internacional. Por otra parte, la diversidad cultural, social, económica y educativa de cada país le da su sello particular a la educación bibliotecológica.

En este contexto tan complejo ¡cómo visualizamos la educación bibliotecológica en nuestra región? El análisis de las escuelas de bibliotecología, listadas en el anexo 1, muestra las siguientes características:

Los títulos de nivel profesional (licenciatura) son diversos en la región, ya que muestran alrededor de once nombres diferentes para denominar al profesional del área bibliotecológica. De esos nombres, algunos muestran la tendencia prevaleciente en la formación que pretende la institución educativa, como los documentalistas de España o los bibliotecólogos de Argentina. En otros casos sólo se le anexan a la bibliotecología otros términos para "ampliar" el espectro de estudios, como la Licenciatura en Bibliotecología y Ciencias de la Información de Bolivia y Chihuahua (México), o la Licenciatura en Bibliotecología y Gestión de la Información que se imparte en España.

Por otra parte siguen existiendo diversos niveles, aún a esta altura de la licenciatura, por ejemplo las diplomaturas que se dan como salida lateral a la licenciatura, el profesorado, el bachillerato técnico superior o el profesional asociado que tienen el 
Flexibilidad curricular en la educación bibliotecológica

mismo nombre que la licenciatura. En todos estos casos, la institución educativa ha definido claramente el perfil del estudiante que se pretende formar y las actividades que éste puede realizar; sin embargo, también tendríamos que preguntarnos si los empleadores tienen esta claridad al solicitar una persona para trabajar en las bibliotecas y demás unidades de información, o les causa la misma confusión que cualquier profesional con el nivel de licenciatura concluido.

Los aspectos en los que todas las instituciones educativas están de acuerdo, aunque no explícitamente, son el perfil de egreso y la visión y misión de la licenciatura y las asignaturas integradas a su plan de estudios, lo que refiere al principal objeto de estudio y de trabajo de los profesionales, en cualquier formato físico que esté contenida: la información.

Por otra parte, en el perfil de egreso se sigue mencionando que los profesionales de las instituciones educativas egresados serán capaces de preservar, organizar y difundir la información en todos sus formatos con la finalidad satisfacer las necesidades de información de la sociedad; de esta forma su campo de acción y sus actividades tienden a ser los mismos: bibliotecas de todo tipo, centros de información, documentación, sistemas de información, archivos y otras unidades en las que se administre la información. Son pocas las instituciones que lleven 
la oferta de campo de trabajo más allá del marco tradicional, incluyendo a las bases de datos, redes de telecomunicaciones, centros de recursos de aprendizaje, entre otros.

A pesar de que el perfil de egreso tenga similitudes y el campo de acción sea el mismo, las asignaturas tienen la misma diversidad que los títulos, aun cuando los contenidos sean similares; los nombres difieren de una institución a otra en más del 50\% del plan de estudios.

Otro dato importante es que el tiempo de estudios varía entre cuatro y cinco años, lo que aumenta el número de asignaturas que tienen las diversas instituciones educativas.

En cuanto al tipo de currículo involucrado, en una sola institución se imparte un $70 \%$ de las asignaturas de forma optativa, de tal modo que el alumno tiene la opción de estructurar su propio currículo; en todas las demás instituciones, las asignaturas son fundamentalmente referidas a la profesión bibliotecológica y al conocimiento teórico e histórico de las bibliotecas, del libro, de los documentos y de la información. Las asignaturas son seriadas o secuenciales bajo una estructura rígida.

Dentro de la estructura mencionada, un área a la que se le ha prestado gran interés es la que se refiere a la tecnología de la información y al aprendizaje sobre redes y recursos electrónicos. Lo anterior se 
Flexibilidad curricular en la educación bibliotecológica

ve reflejado en los planes de estudio, ya que es en la biblioteca y demás unidades de información en donde se ocupan constantemente estos recursos para realizar las diversas actividades.

Respecto a la aplicación de la tecnología en el ámbito bibliotecario, Hinojosa (1983) señala que:

La aplicación de tecnología computacional en las bibliotecas... es una necesidad y una posibilidad a la que ya no podemos ser fácilmente indiferentes. En nuestro trabajo la captura, organización y transferencia de información que requerimos, generalmente, de una amplia flexibilidad que permita la generación de diversos subproductos a partir de la captura de una serie de datos. Esto, sencillamente no se puede lograr con los tradicionales sistemas manuales que habían permitido el desarrollo de la bibliotecología hasta la década de los 60 .

En este sentido cabe hacer la reflexión de que las instituciones de educación bibliotecológica han incorporado a sus planes, áreas y asignaturas, conocimientos sobre las redes y recursos tecnológicos aplicados en la bibliotecología. Sin embargo, y de acuerdo a un estudio realizado por Juan Marcos Recio (2005) se indica que no hay un eje transversal que proporcione a estudiantes y maestros el uso de los medios como recurso didáctico aplicable a cualquier tipo de asignaturas. 
Por otra parte existen planes en los que se ha abusado de la inclusión de asignaturas referidas a la tecnología, considerando que ésta es uno de los fines de estudio del nivel profesional y no sólo el medio para llevar a cabo sus actividades.

Es decir, al profesional de la bibliotecología se le deben brindar los elementos tecnológicos que apoyen y mejoren sus actividades profesionales, pero no tiene porque convertir a la computadora y los sistemas automatizados en su fuente principal de estudio.

Finalmente es importante mencionar la "imagen" del profesional que se está formando a través de los diferentes planes de estudio de la región. $\mathrm{Mu}$ cho se ha insistido, y seguiremos haciéndolo, en que el trabajo que realiza el profesional del área bibliotecológica requiere de una vocación de servicio, pero su imagen como "apoyo a la educación" o de "intermediario" entre la información y el usuario es la postura sobre la que se tiene que reflexionar, ya que ni los apoyos ni los intermediarios son indispensables para el desarrollo social, en cambio la profesión bibliotecológica sí ha sido necesaria y ahora, con la sociedad del conocimiento, no sólo retoma ese papel sino que además permite que sus profesionales amplíen los espacios de acción, y que la información, y por tanto quienes la administran, sean la base del desarrollo de esa sociedad. 
Flexibilidad curricular en la educación bibliotecológica

\section{A manera de conclusiones}

De acuerdo con el análisis de los planes de estudio y coincidiendo con algunas opiniones de los autores antes citados, podemos llegar a las siguientes conclusiones:

Los títulos que denominan a la profesión bibliotecológica en Iberoamérica son tan diversos como sus planes de estudio, lo que nos lleva a pensar en la falta de identidad y seguridad que prevalece en la profesión y en su objeto de estudio. Algunas instituciones sólo responden a la moda en el nombre y otras realizan un cambio en su currículo de acuerdo con la tendencia que quieren reflejar en su designación, pero habrá que reflexionar sobre la vinculación del título, del perfil de egreso, del objetivo de la licenciatura y del mapa curricular con el campo de trabajo, para determinar si esta diversidad refleja lo que es más adecuado.

A pesar de que se tiene un mercado profesional común no existe un perfil homogéneo que permita conocer, a nivel internacional, las características de un profesional de la bibliotecología que pueda desempeñarse en cualquier parte del mundo. Lo anterior se debe a que las instituciones educativas actúan de forma autónoma generando su propio currículo y el perfil de egresado que quieren formar en cada institución educativa. Lo anterior no es incorrecto pero habrá de ubicarse en el contexto de 
globalización y mercado común, en el que el profesional del área bibliotecológica debe mostrar la misma calidad y competencia en cualquier país. En ese sentido, se han hecho esfuerzos valiosos por parte de asociaciones como la Asociación de Educadores e Investigadores en Bibliotecología, Archivología, Ciencias de la Información y Documentación de Ibero América y el Caribe (EDIBCIC) y el Colegio Nacional de Bibliotecarios (CNB), por establecer núcleos de conocimientos bibliotecológicos que proporcionen este perfil bibliotecológico, pero han sido ignorados por las escuelas.

La estructura de los planes de estudio vigentes sigue siendo rígida, lo que impide la posibilidad de revalidar estudios en otras instituciones y hace que la formación sea tan específica que sólo responde parcialmente a los requerimientos de la sociedad.

En cuanto al tiempo de duración de los estudios profesionales éste va de cuatro a cinco años y esto, que parecería irrelevante, es importante para efectos de calidad en la formación profesional y no necesariamente porque el plan de estudios de cinco años sea de mejor calidad que el de cuatro, sino que por simple imagen social lo parecería: pues se piensa que "si tienen mayor tiempo en la escuela entonces tendrán mejor preparación”. En este sentido, las instituciones educativas deben reflexionar si realmente se está formando a mejores profesionales 
Flexibilidad curricular en la educación bibliotecológica

o simplemente se está dando esta imagen social afectando la inserción de los profesionales al mercado de trabajo, así como al proyecto de movilidad estudiantil, la homologación, la compatibilidad curricular, etcétera.

El tipo de currículo bibliotecológico, pese a que las tendencias en la literatura pedagógica y en organismos internacionales como UNESCO y ANUIES se proclaman por el currículo flexible, sigue siendo rígido; es decir, con asignaturas secuenciales y establecidas previamente por las autoridades institucionales. Pocas instituciones ofrecen un tronco común de dos años y opciones de especialización en los otros dos: bibliotecología, gestión, organización. En este punto la reflexión tendría que llevarse en primera instancia hacia lo que se entiende por flexibilidad curricular y si ésta es necesaria para formar bibliotecólogos en Iberoamérica.

La tendencia disciplinar es en general, eminentemente bibliotecológica y teórica en cuanto al conocimiento de la disciplina y su entorno teórico. Se encuentran áreas y conocimientos comunes con la organización bibliográfica, la indización, la catalogación, los servicios a usuarios, etcétera. Esta tendencia habría que ubicarla en un contexto internacional y anexar las competencias y habilidades que requiere un profesional para responder a dicho contexto. 
La imagen del profesional que se presenta en el perfil de egreso de todas las instituciones educativas es de apoyo o intermediario de la información; bibliotecólogos, bibliotecónomos, documentalistas, etcétera. Siguen dando esta imagen de apoyo y seguimos creyendo que lo somos. Debemos trabajar mucho para alcanzar un cambio real de esta imagen a partir de la importancia verdadera que tiene este profesional para el desarrollo de la sociedad.

Todos los aspectos anteriores se vinculan con el campo de trabajo de los profesionales, si se tiene un campo de acción común, ¿cuál es el sentido de tener tal dispersión en los títulos y planes de estudio?

\section{Bibliografía}

Aftasí, Grupo (1998), "Los profesionales de la Biblioteconomía y Documentación ante la Sociedad de la Información: el Proyecto INFODEX", Anales de Documentación 1,: pp. 9-19.

Barberena Blásquez, Elsa, "La enseñanza de la bibliotecología y ciencia de la información: situación en las universidades argentinas", en INFOBILA como apoyo a la investigación y educación bibliotecológica en América Latina y el Caribe, Calva González, Juan José y Martínez Arellano, Filiberto Felipe, Eds. México, UNAM, Centro Universitario de Investigaciones Bibliotecológicas, 2005. 
Flexibilidad curricular en la educación bibliotecológica

Barberena Blásquez, Elsa y Carrión Rodríguez, Guadalupe (2003), "La globalización y los programas de estudio en bibliotecología y estudios de la información", en Biblioteca universitaria: revista de la Dirección General de Bibliotecas, nueva época, julio-diciembre 2003, vol. 6 (2), pp. 116-126.

Baró, Mónica and Cosials, Àlex (2003), "School librarians to facilitate an educational change process", en Proceedings 69th IFLA General Conference and Council, Berlin (Germany).

La Educación bibliotecológica en México a través de sus instituciones educativas. Comp. Lina Escalona Ríos. México, CUIB, 2005, 180 p.

Escalona Ríos, Lina, El mercado de trabajo del bibliotecólogo y su vinculación con la formación y certificación profesional, México, la Autora, 2004, 506 p. Tesis, (Doctora en Bibliotecología y Estudios de la Información) Universidad Nacional Autónoma de México.

Hinojosa, Rogelio, Aplicación de microcomputadoras en biblioteca : la experiencia del ITESM”, p. 111-120, en Jornadas Mexicanas de Biblioteconomía (14, 1983, Zacatecas, Zac.) Memorias, México, AMBAC, 1983. 
INFOBILA como apoyo a la investigación y educación bibliotecológica en América Latina y el Caribe, Calva González, Juan José y Martínez Arellano, Filiberto Felipe, eds. México, UNAM, Centro Universitario de Investigaciones Bibliotecológicas, 2005.

López Segrera, Francisco, Globalización y educación superior en América Latina y el Caribe: la universidad como agente de cambio de transformación social. Caracas : UNESCO, 2001.

Mastromatteo, Estela (2005), Bases, fundamentos y perfil profesional aporte para el cambio curricular de la $E B A-U C V$, Magister Scientiarium in Information and Communication for Development, Comisión de Estudios de Postgrado, Universidad Central de Venezuela, (Venezuela).

Moreiro González, José Antonio (2001), "Licenciatura en Documentación: experiencias, desarrollo, y problemática. El caso de la Universidad Carlos III de Madrid", en Anales de Documentación 4, pp.151-168.

Moscoso, Purificación (1998), Perfil profesional y formativo de los alumnos de la Facultad de Documentación de la Universidad de Alcalá, en Anales de Documentación 1, pp. 155-170. 
Flexibilidad curricular en la educación bibliotecológica

Muñoz Feliu, Miguel C. (1996), Consideración social y papel del especialista de la información en la Valencia de finales de siglo", en Métodos de Información (MEI), 3 (9), pp. 16-20.

Pagaza García, Rafael (2003), "El Profesional Asociado: primer ciclo de formación de las licenciaturas que ofrece la Escuela Nacional de Biblioteconomía y Archivonomía", en XXXIV Jornadas Mexicanas de Biblioteconomía, Puerto Vallarta, Jalisco (México), pp. 109-120.

Pirela Morillo, Johann, “Tendencias y perspectivas para la enseñanza de la bibliotecología en la cibersociedad", en Coloquio de Investigación bibliotecológica, México, CUIB, 2005.

Recio, Juan Marcos, "Herramientas docentes al servicio de la bibliotecología mexicana", p. 231-242, en Coloquio de Investigación Bibliotecológica (22, 2005, México) Memorias, México, UNAM, Centro universitario de Investigaciones Bibliotecológicas, 2005.

Quiroz de García, Rosalía (2005), "El tema de las bibliotecas públicas en el currículo de formación profesional (UNSM-PERÚ)", Pez de Plata : Bibliotecas Públicas a la Vanguardia (4). 
La educación bibliotecológica en Iberoamérica

Serreta Soria, María Gladys, La educación y la investigación en bibliotecología en el Uruguay : estado actual y perspectivas de futuro.

Setién, Emilio, "Tendencias de la formación bibliotecológica en la América Latina”, 7 p., en 3er Encuentro de Educadores e Investigadores de Bibliotecología, Archivología y Ciencia de la Información de Ibero América y el Caribe, Recinto de Río de Piedras, Universidad de Puerto Rico, 1996.

Tarango, Javier y Lau Noriega, Jesús (2003), "Procesos de cambio curricular en ciencias de la información : caso UACH", en XXXIV Jornadas Mexicanas de Biblioteconomía, pp. 131-150, Puerto Vallarta, Jalisco (México). 


\section{Anexo}

Argentina

> Escuela Interamericana de Bibliotecología.

- Biblioteca Nacional de la República Argentina.

Bolivia

- Universidad Mayor de San Andrés. Brasil

- Universidade de Brasília, Departamento de Ciência da Informação e Documentação.

- Universidade Federal de Minas Gerais, Escola de Biblioteconomia.

Colombia

- Pontificia Universidad de Antioquia Escuela Interamericana de Bibliotecología.

- Universidad de La Salle. Facultad de Bibliotecología y Archivística.

Costa Rica

- Universidad Nacional, Heredia, Escuela de Bibliotecología Documentación e Información.

Cuba

- Universidad de La Habana, Facultad de Comunicación. 
Chile

, Universidad Tecnológica Metropolitana.

España

, Universidad Complutense de Madrid. EUBD.

- Universidad de Granada. Facultad de Biblioteconomía y Documentación.

Guatemala

- Universidad de San Carlos de Guatemala.

México

- Secretaría de Educación Pública. Escuela $\mathrm{Na}$ cional de Biblioteconomía y Archivonomía.

- Universidad Autónoma de Chihuahua. Licenciatura en Bibliotecología y Ciencia de la Información.

- Universidad Autónoma de Chiapas Licenciatura en Bibliotecología.

- Universidad Autónoma de Guadalajara. Licenciatura en Ciencias de la Información.

- Universidad Autónoma de Nuevo León. Licenciatura en Bibliotecología.

- Universidad Autónoma de San Luis Potosí, Licenciado en Bibliotecología e Información.

- Universidad Autónoma del Estado de México. Licenciatura en Ciencias de la Información Documental.

- Universidad Nacional Autónoma de México, Licenciado en bibliotecología y estudios de la información. 
Flexibilidad curricular en la educación bibliotecológica

Paraguay

- Universidad Nacional de Asunción. Facultad Politécnica. Escuela de Bibliotecología. Perú

- Pontificia Universidad Católica del Perú, Bibliotecología y Ciencia de la Información.

Puerto Rico

- Universidad Interamericana de Puerto Rico, Maestría en Ciencias Bibliotecarias y de la Información.

- Universidad de Puerto Rico, Escuela Graduada de Bibliotecología y Ciencia de la Información.

Uruguay

- Universidad de la República Oriental del Uruguay.

Venezuela

, Universidad Central de Venezuela. Bibliotecología y Archivología. 


\title{
Método de ensino e aprendizagem para o desenvolvimento humano integrado do profissional da informação
}

\author{
SUELI ANGÉLICA DO AMARAL
}

\section{Introdução}

A s mudanças que estamos vivenciando clamam 1 por uma nova lógica e uma nova ciência, consideradas capazes de promover o entendimento da inteligência social e humana. Diante dessa realidade, na área de Biblioteconomia e Ciência da Informação, quando são preparados profissionais para atuar no setor de informação, as preocupações do professor voltam-se para um mercado de trabalho onde os desafios do profissional da informação do século XXI são enormes.

Trata-se da demanda de um profissional cujo contexto de atuação na nova era deve considerar a relevância e transdisciplinaridade da informação e o novo perfil das unidades de informação, ampliando a visão técnica em favor da interação que acom- 
Flexibilidad curricular en la educación bibliotecológica

panha o desenvolvimento do conhecimento e as mudanças na sociedade.

Embora seja significativo o crescimento das atividades do setor de informação na economia ocidental, pouco progresso houve no que diz respeito aos estudos sobre o setor de serviços em geral, e particularmente sobre as atividades de informação, enfatizando a perspectiva humana da sociedade pósindustrial, no esforço de traduzir em ação nessa sociedade em mudança, uma nova visão da realidade no contexto educacional das áreas de Biblioteconomia e Ciência da Informação, fazendo com que os métodos de ensino e aprendizagem incorporem a flexibilidade curricular e além disso, valorizem a formação integrada dos estudantes.

A globalização da economia aumentou a competição entre as empresas, fato que transformou a informação num diferencial cada vez mais relevante. Em conseqüência, as profissões que lidam com a informação, esteja ela registrada nos mais diversos suportes, do livro ao CD-ROM, passando por toda diversidadeimaginável e talvez ainda não imaginável por alguns de nós, deveriam ser profissões valorizadas no contexto em que vivemos.

$\mathrm{Na}$ realidade não é tão simples assim. Embora a informação seja considerada insumo básico para promover o desenvolvimento econômico e social, para atuar no século XXI, o profissional da infor- 
Método de ensino e aprendizagem para o desenvolvimento ...

mação deverá estar preparado para exercitar sua imaginação, adaptando-a à realidade, onde a criatividade e a dialética são dominantes. Sua criatividade deverá conduzi-lo à inovação. Ele debe estar preparado para desenvolver suas idéias e converter sua imaginação em realidade, criando novos produtos e serviços. A dialética é sua capacidade de dialogar e o diálogo exercita a argumentação, treinando o profissional para a negociação.

Portanto, a preocupação dos professores deve estar voltada também para a formação acadêmica e a educação continuada dos profissionais dessas áreas numa perspectiva mais ampla, capacitando esses indivíduos a atuarem efetivamente no setor de informação, diante dos desafios impostos pela sociedade da informação e do conhecimento.

\section{Fundamentos teóricos}

A realidade ora discutida é baseada no estado de conscientização sobre interrelação e interdependência essenciais para o processo de ensino e aprendizagem e auto-conhecimento, com a adoção de metodologia participativa e vivencial, visando promover o auto-conhecimento como estratégia para melhorar os processos interpessoais e propiciar oportunidades para vivenciar experiências que auxiliem no desenvolvimento do potencial do indivíduo como ser humano integrado no exercício das 
Flexibilidad curricular en la educación bibliotecológica

práticas profissionais. Essa visão se estende além das fronteiras disciplinares e conceituais. Devem ser desenvolvidas novas formas de pensamento a serem adotadas em conformidade com os novos princípios usados pelas organizações e comunidades, em processo de criação e transformação.

O método de ensino e aprendizagem nas áreas de Biblioteconomia e Ciência da Informação poderá ser aplicável tanto para a formação acadêmica em nível de graduação como na pós-graduação, adequando-se aos programas de educação continuada, pela sua rede de interconexão de conceitos e modelos. Além disso, ao mesmo tempo, deverá servir ao desenvolvimento do indivíduo como um ser total.

Os princípios filosóficos a serem trabalhados por cada indivíduo pela sua participação dentro e fora da sala de aula permitirão viabilizar uma condição apropriada para essa unidade desenvolvida pelo próprio indivíduo.

O princípio de dinâmica da dialética participativa é empregado pela interação dinâmica em sala de aula com o empenho de criar oportunidades de participação de todos em busca de soluções para os questionamentos individuais e coletivos.

O desenvolvimento da razão e da intuição traz a tona a base de uma sensibilização inicial, que é obtida de acordo com a busca da identidade de uma profissão com o seu profissional; o desenvolvimen- 
Método de ensino e aprendizagem para o desenvolvimento ...

to da motivação que traz o estudante para aquela sala de aula em particular; a permissão para eliminar conteúdos emocionais ou pensamentos relacionados a conceitos inIbídores, que possam bloquear o processo da aprendizagem; o começo do diálogo baseado na interação entre "eu" e o "outro"; a reorganização social do relacionamento do grupo; obter do grupo um produto mensurável, acabado, tangível ou intangível.

Isso permitirá ao aluno: encontrar sua própria identidade; desenvolver a sensibilização da sua própria pessoa e do outro; ampliar sua capacidade de dialética participativa na avaliação de situações; entender a estruturação de conteúdos e a organização sistêmica.

O desenvolvimento de cada aluno será buscado pela expansão do nível de consciência de cada um.

\section{História do Método IBIS}

Com o pensamento voltado para a valorização do ser humano na sociedade, em 1986, a Professora Tânia Mara Botelho, da Universidade de Brasília, Brasil, criou o método IBIS.

Durante sua fase de desenvolvimento, os resultados de pesquisa foram apresentados e discutidos em eventos internacionais, em 1993, durante a Second World Conference on Continuing Professional Education for the library and Information Science 
Flexibilidad curricular en la educación bibliotecológica

Professions, organizada pela International Federation of Library Associations and Institutions (IFLA) Continuing Professional Education Round Table (CPERT), em Barcelona, Espanha (Botelho \& Amaral, 1993) e em 1994, durante a 47th International Federation for Information and Documentation Conference and Congress, em Tóquio, no Japão, FID Education and Training Pre- Conference Seminar sobre Multifunctional information new demands for training (Botelho \& Amaral, 1994).

O método IBIS leva os participantes a se desenvolverem integralmente como pessoas. Sua concepção envolve um estudo de Lógica, relacionado à razão e à intuição. Incorpora um novo conceito de Física Quântica, que propicia a adoção da abordagem holística, permitindo o desenvolvimento necessário à formação e educação continuada de profissionais habilitados a dirigir o setor da informação baseado em novos princípios comportamentais.

Baseia-se na educação reflexiva, apresentando uma abordagem à luz da evolução da nossa sociedade. Desafia as pessoas envolvidas, professores e alunos, a se conhecerem melhor, adaptando-se as suas próprias modificações comportamentais exigidas pelo método. De modo geral, os envolvidos reagem efetivamente a essa evolução, especialmente, os alunos. A discussão sobre o método abrange 
Método de ensino e aprendizagem para o desenvolvimento ...

muitos aspectos, incluindo a explicação das perspectivas humanas, os fundamentos das modificações comportamentais e da educação reflexiva.

O método IBIS envolve a educação reflexiva, que exerce um importante papel, desde o preparo do indivíduo para a melhoria da qualidade de vida, até o encontro com ele mesmo e o seu ambiente de trabalho. O ensino reflexivo, segundo Calderhead (1989) "aborda o treinamento e desenvolvimento profissionais associados às noções de crescimento por meio de questionamento crítico, análise e auto-avaliação". Por essa razão, a educação reflexiva foi a base fundamental desse método de ensino e aprendizagem, inspirado no conceito de Bruner (1972) sobre a aprendizagem por descoberta, enfatizando a importância da liberdade para ensinar.

As ênfases teóricas sobre a reflexão no processo educativo variam de acordo com: as características do estabelecimento e implementação de soluções, o emprego de bases particulares do conhecimento, as habilidades analíticas, as atitudes facilitadoras da abordagem reflexiva, os níveis do auto-conhecimento e da auto-determinação, o exame dos valores e princípios éticos e a apreciação de ideologias e adversidades.

De acordo com os estudos realizados por Carr \& Kemmis (1986), a ação da pesquisa em educação pode ser abordada segundo quatro características: o 
Flexibilidad curricular en la educación bibliotecológica

processo, o conteúdo, os pré-requisitos e o produto. $O$ processo diz respeito à reflexão na ação e deliberações curriculares. O conteúdo distingue os próprios valores dos professores, o contexto social e a teoria educacional. Os prérequisitos são a atitude para a reflexão no contexto tutorial em que ela ocorre.

Como produto será obtida uma aprendizagem efetiva por meio da emancipação e entendimento da relação mantida entre os valores preconizados e a prática exercida.

O método IBIS pressupõe a necessidade de facilitar o aprendizado para ensinar. Por ter sido desenvolvido no Brasil, fundamentou-se, basicamente, em um dos princípios da educação brasileira, preconizados no artigo 206 da Constituição de 1988, observando a necessidade da "liberdade de aprender, ensinar, pesquisar e divulgar o pensamento, a arte e o saber".

A liberdade para ensinar e a liberdade para aprender foram as premissas do método IBIS, expandindo a macrovisão do mundo pela interação com o ambiente pessoal e relacional das organizações, bem como enriquecendo a microvisão, a partir do mundo interior. Assim, o conhecimento aprimorado do ambiente conduzirá as pessoas ao auto-conhecimento, facilitando a interação de cada pessoa com a outra. A adoção do método implica o 
Método de ensino e aprendizagem para o desenvolvimento ...

uso de técnicas de sensibilização, o desenvolvimento de habilidades e a avaliação do processo de crescimento, evitando-se julgamentos obtidos pela racionalização danosa à liberdade de ser.

As mudanças ocorridas e os novos valores assimilados levam os alunos a obterem melhores resultados, adquirindo uma visão estratégica de cada situação.

Para tanto é enfatizada a importância da plena atenção a todas as ocorrências e circunstâncias que permitam alcançar o equilíbrio dinâmico de cada um. A autoconscientização do aluno referente ao seu papel na sociedade leva-o a ampliar sua interação consigo mesmo, nos seus diversos ambientes: familiar, social, profissional e humano. Atingir a auto-consciência abrange a percepção da unidade e da totalidade. É imprescindível estar auto-motivado, aprendendo a comunicar e transmitir idéias, além de entender a complexidade da abordagem sistêmica do universo. A auto-consciência exige o exercício da atenção plena, da observação e da vivência que levam à sabedoria. A auto-motivação dos alunos é alcançada exercitando-se a criatividade, o desenvolvimento pessoal, a educação reflexiva e o desapego. Para tanto, é necessário que os alunos percebam a necessidade de desistir da dominação e do exercício da força e do poder manipulativos sobre as demais pessoas. Para realizar a comunicação 
Flexibilidad curricular en la educación bibliotecológica

e transmissão de idéias com êxito é necessário, antes de tudo, saber ouvir e ver-se no outro, exercitando a empatia.

Por fim, o aluno desenvolverá a percepção acurada, tornando-se receptivo, aprendendo a compreender e agir em sintonia com a sua realidade interior, harmoniosamente com a realidade exterior. A abordagem sistêmica do universo fundamenta-se na lógica da razão e da intuição, visando a estruturação dos conteúdos e dos diversos ambientes, reprogramando o nosso interior e adaptando-o às circunstâncias em que vivemos.

O método utiliza a observação do rendimento dos alunos em relação aos objetivos pretendidos pelo curso, de acordo com os critérios constantes da folha de avaliação individual do aluno e as variáveis do ensino e da aprendizagem. O processo utilizado pelo método abrange as relações psicossociais estimuladas pela participação dialética, pela cultura ambiental e pela motivação, usando como recursos: música, transparências, imaginação, checklist e avaliação. A abrangência do processo desenvolve as habilidades dos sensos de determinação, criatividade, oportunidade e organização de cada aluno. Desenvolvidos plena e integralmente, a mudança comportamental dos alunos submetidos ao método IBIS é o produto decorrente da adoção desse método de ensino e aprendizagem. A avaliação de cada 
Método de ensino e aprendizagem para o desenvolvimento ...

aluno é feita tanto em nível cognitivo, quanto de habilidades. O estado de espírito de cada um será observado pelas manifestações de alegria, felicidade e pelo bem-estar. A auto-expressão será refletida pelo melhor conhecimento e uso total da potencialidade de cada um nas atividades pessoais e profissionais.

A ênfase teórica da avaliação tem lugar no processo de educação reflexiva, onde o processo educacional varia de acordo com as características da implementação de soluções, o uso em particular de bases cognitivas, habilidades de análise, atitudes que facilitem a abordagem reflexiva, níveis de autoconhecimento e auto-determinação, exame dos princípios e valores éticos e a apreciação de ideologias e adversidades. Assim, os adotantes do método pasma a encarar a avaliação como parte integral do processo de ensino e aprendizagem, tanto os professores quanto os estudantes.

O ser humano precisa ser feliz, por isso ele precisa desenvolver o seu próprio potencial para ampliar sua capacidade de administrar o sucesso na sua vida. Para isso nós precisamos desenvolver nosso auto-conhecimento, tentando significativas mudanças de atitudes, valores e hábitos. Assim, o autoconhecimento é o resultado de uma aprendizagem e de um processo de reeducação pessoal. 
Flexibilidad curricular en la educación bibliotecológica

Nós precisamos saber usar nossos sentimentos, atenção, capacidade de observação, memória, intuição e racionalidade para ampliar nossa capacidade de percepção. É preciso aprender a ver, ouvir e sentir. Precisamos prestar atenção no desenvolvimento da nossa capacidade de observar. As pessoas são diferentes e isso é importante para entender e ser bem sucedido nas relações interpessoais.

As mudanças que ocorrem e os novos valores que são assimilados trazem melhores resultados para os estudantes quando eles adquirem a visão estratégica de cada situação. Logo, o auto-conhecimento dos estudantes em função de seus papéis na sociedade resultam na ampliação das suas inter-relações com eles mesmos e com os ambientes em que vivem junto à família, no âmbito social e no profissional. Atingir o auto-conhecimento abrange a percepção da unidade e da totalidade.

Auto-motivação requer mais que intenção. É necessária ação efetiva e contínua para criar a capacidade mental para construí-la. Os estudantes alcançam a auto-motivação exercitando a criatividade, desenvolvimento pessoal, educação reflexiva e imparcialidade. Isto é indispensável para aprender, comunicar e transmitir idéias, bem como entender a complexidade da abordagem sistemática do universo. Torna-se necessário aprender a comunicar-se com sucesso, aprendendo como prestar atenção ao 
Método de ensino e aprendizagem para o desenvolvimento ...

ouvir e apreciar a si mesmo e aos demais, usando empatia nesse processo.

\section{Considerações finais}

O método IBIS é essencialmente sistêmico. Caracteriza-se pela sua flexibilidade de adaptação às necessidades individuais e supera as inadequações das abordagens que não acompanham a evolução imposta pela sociedade, respeitando os valores humanos.

A constante avaliação do método é necessária. A adoção de novos paradigmas nos métodos de ensino e aprendizagem, compatíveis com a evolução da sociedade, valorizando a flexibilidade, qualidade, harmonia e conciencia coletiva contribuirá positivamente tanto na formação de novos profissionais, como para a educação continuada dos atuais profissionais. Mais do que nunca o perfil profissional adequado à atuação no século XXI deverá enfatizar o desenvolvimento humano. Além disso, novos indicadores de avaliação devem ser construídos e validados.

Desenvolver programas de ensino que valorizam o ser humano, valorizando o ambiente operacional com o desenvolvimento de habilidades técnicas associadas ao estímulo à inovação, criatividade e novos valores de qualidade de vida é essencial. 
Flexibilidad curricular en la educación bibliotecológica

Portanto, os professores devem estimular o desenvolvimento da autoconciencia de seus alunos, preparando-os para o futuro. Isto implica em incluir esses critérios no conteúdo dos cursos ministrados, sejam eles em qualquer grau, em nível profissionalizante, de graduação, aperfeiçoamento, ou de pós-graduação.

O método IBIS permite ao professor e principalmente aos estudantes melhorarem eu relacionamento. Proporciona ao estudante o encontro de sua identidade, sensibiliza-o para perceber melhor a si próprio e ao outro, incentivando a participação dialética, a capacidade de avaliação das situações, estruturando os conteúdos com sua organização sistemática.

É possível considerar essa proposta como forma de enfatizar a necessidade do desenvolvimento humano na preocupação com o aproveitamento de todo o potencial de cada indivíduo, preparando profissionais capazes de obter o desempenho profissional esperado para aqueles que atuarão na sociedade em transformação no século XXI.

Assim, todas as sugestões serão bem recebidas e os interessados na aplicação do método poderão solicitar as necessárias informações. 
Método de ensino e aprendizagem para o desenvolvimento ...

\section{Referências}

Botelho, Tânia Mara, "The equilibrium of forces and challenges within the quaternary information sector", en: International Conference on the knowledge industries: levels of economic and social development in the 1990, Dubrovinik, Yugoslavia, May 29 June 3, 1989.

Botelho, Tânia Mara, Amaral, Sueli Angelica do, Continuing Education in the information profession: a reflective method, en: Continuing Professional Education and IFLA: past, present, and a vision for the future Papers from the IFLA CPERT, Second World Conference on Continuing Professional Education for the Library and Information Science Professions, edited by Blanche Woolls. München,: K.G.Saur, 1993, 365p., p.202-209, (IFLA Publications, 66/67).

Botelho, Tânia Mara, Amaral, Sueli Angelica do, "Information professional education and training for a new management paradigm in developing countries", en: International Federation for Information and Documentation. Conference and congress, 47, Tokyo, 1994. FID Education and Training Pre-Conference Seminar, working papers Multifunctional information new demands for training?, Tokyo : FID / UNESCO, 1994, pp.20-28. 
Flexibilidad curricular en la educación bibliotecológica

Bruner, J. O, processo da educação, São Paulo, Nacional, 1972, 88p.

Calderhead, James, "Reflexive teaching and teacher education", en Teaching E Teacher Education, v. 5, n. 1, pp.43-51, 1989.

Carr, W.; Kemmis, S. Becoming critical: education knowledge and action research, London : Falmer Press, 1986. 


\section{Currículo formal de bibliotecología en la Universidad Autónoma de Chiapas, Facultad de Humanidades Campus VI}

ROSA ELbA CHACÓN ESCOBAR

\section{Introducción}

Tas reflexiones que me permitiré abordar en el - 1 presente trabajo se basan en las lecturas efectuadas, y en las preguntas que me he hecho sobre flexibilidad curricular y las tendencias de la educación bibliotecológica señaladas para ser discutidas en el Foro Académico del Seminario de Educación bibliotecológica, CUIB.

El Currículo es una propuesta educativa que incluye la selección de un conjunto de objetivos que deben alcanzarse mediante la educación, la estructura curricular y las partes que conforman el currículo. Es decir, al estructurar un currículo se crea 
Flexibilidad curricular en la educación bibliotecológica

un plan de estudio y contenidos esquemáticos, adyacentes, pedagógica y administrativamente.

La flexibilidad curricular supone la introducción de un modelo organizativo abierto, dinámico y polivalente que permita transformar las estructuras académicas rígidas y producir nuevas formas de organización mediadas por la interdisciplinariedad y el trabajo integrado que es más autónomo y está mejor orientado hacia el aprendizaje de nuestros estudiantes.

Para este foro el currículo formal en bibliotecología es el Plan y Descripción Curricular de la Licenciatura en Bibliotecología de la Facultad de Humanidades, UNACH, documento que fue aprobado en la sesión ordinaria del Consejo Universitario celebrada el 26 de septiembre de 1992. La creación de la Licenciatura en Bibliotecología se dio a conocer en el Proyecto Académico 1991-1994 de la UNACH en junio de 1991. El currículo de bibliotecología pretende formar a profesionales capaces de atender y responder a los planteamientos de su práctica profesional; hacer accesible al estudiante las bases humanísticas y técnicas; desarrollar actitudes y habilidades que lo capaciten para asesorar y orientar adecuadamente a los usuarios en la utilización; y aprovechar óptimamente los recursos y servicios bibliotecarios para satisfacer las necesidades de información documental y los intereses de recreación y 
Currículo formal de bibliotecología en la Universidad ...

auto educación de los usuarios. Según lo descrito en el plan de estudios:

Formar bibliotecarios profesionales que, mediante la comprensión de los fundamentos filosóficos, científicos y técnicos de la especialidad, así como de otras disciplinas afines y la aplicación racional de las teorías y técnicas respectivas, satisfagan las necesidades de información documental de sus usuarios y sus intereses en cuanto a autoeducación y recreación (Plan LB, 1992: 48).

La licenciatura se planeó para realizarse en nueve semestres, durante los cuales el alumno deberá cursar 49 materias o asignaturas con carácter obligatorio, y tres semestres de inglés extracurricularmente. El total de créditos es de 429, de los cuáles 328 son de orden teórico, y 101 de carácter práctico.

Los créditos que los alumnos deben cursar corresponden a 39 asignaturas teóricas y/o prácticas, 4 seminarios y 6 talleres (Plan LB, 1992).

Los elementos que contiene el Plan de Estudio de Bibliotecología son: Introducción; Antecedentes y justificaciones; Marco referencial: Infraestructura bibliotecaria en Chiapas, Revisión teórica y trabajo curricular; y Etapas del trabajo curricular.

Otras Universidades que ofrecen esta licenciatura incluyen el Plan de Estudio de la Licenciatura en Bibliotecología: Fundamentación bibliotecológica; Propósito general y propósitos particulares; Perfil 
Flexibilidad curricular en la educación bibliotecológica

del profesional. Otro Plan de estudios ofrece: Número de créditos; Especificaciones administrativas; Lengua extranjera; Metodología de la carrera; Duración estimada de la Carrera; Descripción de los Contenidos Generales del Mapa Curricular, entre los que están las Normas Generales: Requisitos de ingreso, evaluación y acreditación; servicio social, Requisitos de egreso y titulación; Secuencia-Seriación de las asignaturas; Carga horaria y asignación de créditos por semestres; Asignación de créditos por áreas de formación; Mapa Curricular; Propósitos de las áreas de formación; Campos de trabajo; Tipo de docente y Plantilla de personal requerido; Información consultada. El Anexo incluye: Descripción analítica del perfil del egresado de la Licenciatura en Bibliotecología de la UNACH (Filosofía bibliotecaria y Ética profesional, Extensión profesional, Sociedad y cultura, Organización y administración, Ciencia y tecnología, Educación-Investigación, Beneficio Social y Marco Legal) (Plan LB, 1992).

Las tendencias de la educación bibliotecológica en la UNACH a partir de los siguientes aspectos:

- Títulos que proporcionan las instituciones educativas

- Tiempo de duración de los estudios

- Tipo de currículo

- Tendencia disciplinar 
- Imagen del profesional según su perfil

- Campo de trabajo

Título que proporciona la Universidad Autónoma de Chiapas

El título universitario que adquiere el egresado una vez acreditado el plan de estudios es el de Licenciado (a) en Bibliotecología.

\section{Tiempo de duración de los estudios}

El plan de estudios fue diseñado para cursarse en nueve semestres. En términos generales, por lo que toca a los datos de los semestres, la carga horaria, los créditos, el carácter, la modalidad, el objetivo general y la descripción temática, éstos vienen descritos por materia. Además de la Carga horaria y Asignación de créditos por semestre, están: Asignación de créditos por áreas de formación; Usuarios de la información; Servicios de información; Tecnología de la Información; Organización de las unidades de Información; Investigación y Sistemas de Clasificación Documental, incluyendo los propósitos que vienen descritos ampliamente en Mapas curriculares.

El número de créditos, como se menciona en el plan de estudios, se conforma por 429 créditos que el alumno deberá acreditar con carácter obligatorio. 
Flexibilidad curricular en la educación bibliotecológica

En cuanto a las especificaciones administrativas, el alumno observará lo dispuesto en el artículo 53 de la ley orgánica de la UNACH. Para la presentación de exámenes, reprobación e inscripción, y en las excepciones consideradas en el reglamento de exámenes, el interesado podrá cursar un máximo de siete materias por semestre, siempre y cuando las materias que curse no sean seriadas.

En cuanto al conocimiento de una lengua extranjera, inicialmente el alumno debía acreditar siete semestres de inglés de manera extracurricular y obligatoria; con la reforma aprobada por el $\mathrm{H}$. Consejo Universitario en 1992, únicamente debe acreditar tres semestres de inglés.

Según lo establecido en el plan de estudios, la carrera funciona desde 1992 en la Facultad de Humanidades y se imparten en las aulas los contenidos temáticos de orden teórico. Los de orden práctico, según corresponda, se cursan fuera de las instalaciones de la facultad.

\section{Tipo de currículo}

El currículum de bibliotecología se sustenta en una corriente constructivista, en la que el alumno tiene la posibilidad de adquirir una gama de conocimientos en los campos educativos, económicos, políticos, sociales y culturales, lo que le permitirá construir sus propios conocimientos y tener un mejor 
entendimiento de los nuevos paradigmas de la información y del contexto social. No hay que olvidar que la sociedad de nuestro tiempo también impone un cambio de paradigma en el proceso educativo, y que hoy se habla de una educación centrada en el alumno y no en el docente.

\section{Tendencia disciplinar}

Con la finalidad de ubicar mejor el rumbo disciplinar que el currículo determinó en 1992, me permito señalar algunos aspectos descritos en el plan de estudios.

El planteamiento y la justificación del currículo de bibliotecología incluyen un diagnóstico que especifica las características y necesidades presentes y futuras de Chiapas y de México, a partir de las exigencias existentes a nivel estatal y regional, que se expresan en los objetivos de la formación que se pretende proporcionar y plantean la necesidad de vincular a la escuela y la sociedad basándose en una formación básica, integral y equitativa que le permita al individuo incorporarse a la nueva dinámica social.

Al fundamentar el currículo de bibliotecología se partió de las necesidades sociales con la intención de ofrecer una nueva opción de formación profesional que integrara un conjunto articulado de estrategias de educación superior tendientes a impul- 
Flexibilidad curricular en la educación bibliotecológica

sar a la Universidad Autónoma de Chiapas hacia los desafíos del siglo XXI y en respuesta a la política de modernización que planteaba en ese momento la administración universitaria.

En la fundamentación también se hace explícita la falta de especialistas en la disciplina bibliotecológica y la necesidad de proporcionar una formación profesional competente que vaya identificando las necesidades de información, y enseñe las habilidades indispensables que permitan la instrumentación de los sistemas tecnológicos y administrativos y satisfagan las necesidades detectadas. Para ello la función deberá incorporar el uso de las tecnologías de la información, y ser capaz de crear y establecer parámetros que ayuden a determinar la organización, rentabilidad y eficiencia en la operación de una biblioteca, conforme a los esquemas normativos vigentes.

Visto así el universo bibliotecológico se presenta con vastedad, aún más en la actualidad debido a los cambios constantes del entorno y el efecto hacía la disciplina misma y la consecuente repercusión en las finalidades de la educación. Ante este marco referencial la información se convierte en un fenómeno que abarca diversos aspectos de la vida social, y que incluso es por sí misma un suceso económico que no puede ser ignorado. Por el contrario, se traduce en la generación de nuevas tecnologías, modificaciones de los métodos tradicionales de publicación, y 
adición de nuevas formas de publicación como el disco compacto, la publicación electrónica, los servicios de información comerciales, etc.; es decir, se convierten en servicios cuyo fin es vender la información e incidir en el desarrollo científico, tecnológico, industrial, económico, e incluso educativo. Esto plantea nuevos esquemas de enseñanza y modifica el desarrollo de la comunidad en sí, al introducir nuevos factores que desplazan a aquellos tradicionales (LB 1992: 45-46).

A catorce años de operación de este programa educativo y tras estas reflexiones, la educación bibliotecológica en la UNACH requiere de un estudio complejo, integral que le permita adecuarse a diferentes contextos en el plano sociocultural, político y económico según sus propias características, y tomar en cuenta las nuevas políticas educativas que en materia de flexibilización curricular han sido emitidas por organismos internacionales como la UNESCO o la ANUIES. Nos referimos a las competencias, destrezas, habilidades, valores y actitudes que requiere el profesional egresado de este plan de estudios. Por lo tanto, la educación bibliotecológica tiene que adecuarse a estos cambios y dejar atrás la tendencia eminentemente bibliotecológica y teórica de la disciplina. 
Flexibilidad curricular en la educación bibliotecológica

\section{Imagen del profesional en su perfil}

Es importante señalar que a través del perfil curricular se delimita el tipo de ser humano que se pretende construir durante el proceso de formación. Para ello debe partirse de un análisis previo que estudie al hombre en general y su entorno social; que evalúe sus carencias y necesidades, y con base en ello, justifique y fundamente la creación del futuro profesional. Contar con un adecuado diseño curricular (perfil de egreso) es tener la posibilidad real de orientar la formación profesional, y de darle sentido y coherencia a los programas educativos.

El perfil del egresado permite dotar efectivamente de contenido educativo a los grandes objetivos del programa. Sólo tras definir las características deseables y viables de los egresados es posible diseñar un plan de estudios coherente, y determinar con precisión el conjunto de recursos humanos, técnicos y materiales que permitan implantar y desarrollar un programa académico de calidad.

Por lo que toca al plan de estudios, lo que se espera del profesional de esta disciplina es que éste sea:

[...]capaz de planificar, diseñar, administrar sistemas de información organizados, manual o computarizadamente, tales como bibliotecas, centros de documentación, archivos y otros, además de generar estrategias que fomenten el uso de los sistemas de información a fin de enfrentar con éxito el creciente desarrollo de la in- 
Currículo formal de bibliotecología en la Universidad ...

formación y su demanda. Mantendrá una permanente comunicación con la comunidad que demanda estos servicios tendrá capacidad para responder a las necesidades de información local, regional y nacional, así como para adecuar y racionalizar el uso de los avances tecnológicos y de las nuevas tecnologías de la especialidad, que se desarrolla en este ámbito (Plan L B, 2001: 50).

Por medio del perfil puede observarse al hombre desde su devenir histórico y visualizarse también al hombre de nuestros tiempos. Pero no sólo eso, sino que también se percibe la manera en que ese hombre ideal va tomando forma y figura durante el proceso de formación académica el cual será guiado principalmente por la práctica docente; en nuestro caso la disciplina bibliotecológica.

El currículo de bibliotecología plantea y define la figura del bibliotecólogo, al mismo tiempo que proporciona la orientación estratégica metodológica que le permitirá entender los diversos fenómenos del campo bibliotecológico involucrados con la información y la globalización del campo bibliotecológico: la información, la globalización, las tecnologías de información y comunicación. El rol del bibliotecario, del especialista en información, bibliotecas y otras unidades de información debe tener bases sólidas que le ayudan a adquirir los conocimientos necesarios para apoyar de manera 
Flexibilidad curricular en la educación bibliotecológica

sustantiva en proceso educativo en sus diversas modalidades (Chacón E.:, 2003).

Formar bibliotecarios profesionales que, mediante la comprensión de los fundamentos filosóficos, científicos y técnicos de la especialidad, así como de otras disciplinas afines y la aplicación racional de las teorías y técnicas respectivas, satisfagan las necesidades de información documental de sus usuarios y sus intereses en cuanto a auto educación y recreación" (Plan LB, 1999:48).

En lo que se refiere a los propósitos particulares establecidos en el plan, éstos pretenden:

- Proporcionarle al estudiante el marco de referencia para comprender la problemática intelectual, institucional, social y cultural implícita en la adquisición y acrecentamiento del saber, al igual que explicarle los orígenes y fundamentos de las ciencias, las letras y la tecnología, como coadyuvantes para el desarrollo de la vida social y la elevación de sus niveles de bienestar.

- Crear nuevas actitudes que superen las anteriores y desarrollar habilidades intelectuales que le faciliten al estudiante la comprensión y aplicación de los principios y técnicas de la administración, a fin de que las diversas funciones bibliotecarias se desarrollen efectiva y eficientemente como un medio eficaz de adquisición, preservación y difusión del pensamiento humano. 
Currículo formal de bibliotecología en la Universidad ...

- Hacer accesible para el estudiante las bases actuales humanísticas y técnicas que lo conviertan en un profesionista capaz. Y desarrollar actitudes y habilidades que le permitan asesorar y orientar a los usuarios en la utilización y el aprovechamiento óptimo de los recursos y servicios bibliotecarios, que satisfagan sus necesidades de información y recreación.

- Imbuir en el futuro bibliotecario las actitudes, aptitudes y habilidades para apoyar, a través de su prestación de servicios de información, a la industria y a la economía en el papel que éstas desempeñan para el desarrollo de México a nivel nacional y mundial, y la educación mexicana en particular (Plan LB 1999).

Sin embargo lo anterior no es una realidad establecida en las acciones de los sujetos que intervienen en el proceso de esa construcción. Entre lo que se desea y se logra existen canales de desviación y mal formación, y el hecho de manifestar los propósitos y pretensiones adecuadas no quiere decir que se alcancen eficazmente los resultados. Para lograr esto sería antes necesaria una verdadera concientización y revaloración de las acciones pedagógicas y también una permanente actualización y capacitación de la planta docente que cubriera los propósitos descritos que enmarca el plan de estudios de bibliotecología. 
Flexibilidad curricular en la educación bibliotecológica

\section{Campo de trabajo}

En lo que se refiere a los Campos de Trabajo se señala que el licenciado en bibliotecología de la UNACH podrá desempeñarse como docente, investigador, operador de terminales automatizadas de información y de centros de cómputo, y como administrador de bibliotecas y como archivista (Plan LB, 1992:130).

Las reflexiones siguientes se relacionan con los problemas que implica la flexibilización curricular, las nuevas estrategias y las ventajas de la instrumentación de éstas.

\section{Consideraciones generales en la formación bibliotecológica de una Currícula Flexible en la UNACH}

La formación bibliotecológica que se impartirá en a Facultad de Humanidades pretende insertarse en una educación eficiente, flexible y de alta calidad, e incluir conocimientos acerca de la realidad, local, regional, estatal, nacional e internacional, además de analizar las características económicas, políticas, sociales y culturales que le permitan abordar los retos y desafíos que habrá de enfrentar el estudiante en proceso de formación.

Aquí el verdadero reto es, cómo abordar todo esto en la práctica y que trascienda el plano del discurso. Seguramente los actores involucrados en 
este proceso tan complejo, coincidimos en que es necesario replantearnos varios aspectos, definir los objetivos de un plan de estudios que implique un escenario de flexibilidad curricular psicopedagógica (con un enfoque centrado en el aprendizaje) y en el programa y la unidad académica (flexibilidad académico administrativa). La flexibilidad curricular deberá conducir hacia una nueva pedagogía y tener presentes los factores que incidirán en el desarrollo de la flexibilidad psicopedagógica y como éstos se relacionan con los siguientes aspectos: formación y actualización docente, y evaluación de capacidades del estudiante. Deberán cambiar también las actitudes tanto del profesor como del estudiante, y las condiciones materiales de operación considerando las posibilidades de transformación de las estructuras y procesos académicos y administrativos.

No hay que perder de vista que con esta perspectiva, el currículo flexible o abierto se cambiará en los procesos del alumno, se sustentará en un paradigma cognitivo, y será interdisciplinario, transdisciplinario y multidisciplinario. Sus objetivos se basarán en capacidades y destrezas, y con valores y actitudes que se pueden ir actualizando en función del contexto; entonces nuestro rol como docentes habrá de transformarse en el de mediador y facilitador del aprendizaje. 
Flexibilidad curricular en la educación bibliotecológica

En este contexto y tomando en cuenta el escenario educativo en el que se desarrolla el plan de estudios de la licenciatura en bibliotecología en Chiapas, es importante resaltar varios factores: la cultura del alumno, la formación docente, las condiciones materiales y la interacción del grupo, que tienen que ser tomados en cuenta si queremos lograr en el alumno un mejor aprendizaje de los contenidos; sin pasar por alto que tanto el emisor como el receptor deben tener un espacio de acción participativa en clases. Si como docentes tomamos en cuenta toda la acción comunicativa que se da en nuestros grupos, esto nos permitiría conocer los sentimientos, las expresiones y las ideas de los alumnos, lo cual nos ayudaría a construir mejores formas de interacción y de enseñanzas grupales que repercutirían en un ambiente de participación en nuestras aulas.

En el salón de clases es fácil para nosotros convertir la participación en información, y para el grupo hacer una intervención verbal que sea aceptada por nosotros. Aunque suele darse también todo lo contrario con una acción pedagógica que le permita al alumno participar y fomentar el diálogo, como lo menciona Paulo Freire "Una exigencia existencial. Y siendo el encuentro que solidariza la reflexión y la acción de sus sujetos encausados hacia el mundo que debe ser transformado y humaniza- 
do, no puede reducirse a un mero acto de depositar ideas de un sujeto en el otro, ni convertirse tampoco en un simple cambio de ideas consumadas por sus permutantes" (Freire, 1970: 106).

Por ello no debemos asumir el papel central de que el docente lo sabe todo en el salón de clases porque esto ocasiona pasividad en el alumno y no lo convierte en un sujeto activo y transformador de su propia realidad.

El diálogo no sólo debe implicar el intercambio de ideas con nuestros alumnos, sino también la reflexión, la expresión de pensamientos que conducirán al alumno a la construcción de su entorno.

Y también debemos fomentar su participación en tareas; dejando que nuestros alumnos reflexionen antes de expresar sus ideas, si logramos compaginar esto en el proceso de enseñanza - aprendizaje, habremos logrado que nuestros alumnos sean críticos, analíticos, reflexivos y participativos en las clases.

Así, nuestra tarea como docentes consiste en organizar sistemáticamente situaciones comunicativas en las que nuestros alumnos puedan hablar, en concebir el proceso como una comunicación didáctica, como un acto creativo donde (maestro - alumno) puedan transformar actitudes. Esto daría lugar a que se abandonara la postura que algunos de nuestros maestros de bibliotecología asumen: la de ser sólo emisores en lugar de constructores y reconstructores. 
Flexibilidad curricular en la educación bibliotecológica

El "[...] ]ser buen maestro, es saber volverse niño y ponerse a su nivel, abrirse a la comprensión total de un niño; se supone que el maestro se de cuenta de que tiene que aprender más del niño que el niño de él" (Charles, 1998: 36). Cuántos de los docentes de bibliotecología comprendemos así nuestro rol educativo e intentamos una comunicación educativa eficaz, en donde la autoridad nazca en el diálogo mismo y no sea exclusiva de ninguno de los integrantes del grupo; en donde dejemos de ser la autoridad y el poder para convertirnos en generadores de alternativas ante los problemas que se plantean en el salón de clases. La autoridad nace de la dinámica misma del grupo, concientemente aceptada por ellos. El docente (emisor) pierde aquí sus privilegios y es aquel que sabe más de algo en un momento determinado, pero debe estar conciente de que ese conocimiento y tiempo no son definitivamente poseídos por él. Ser docente pierde, en este contexto, su significado de poseedor de privilegios y lo convierte en un buscador constante de respuestas a las necesidades que nuestros grupos plantean; esto debe suponer una reparación continua en los conocimientos específicos de aquellos que integran el grupo.

Como docentes debemos entender que nuestra práctica ya no es la de trasmisores del conocimiento. Más bien nuestros alumnos habrán de convertirse en descubridores de conocimientos que adqui- 
Currículo formal de bibliotecología en la Universidad ...

rirán al dejar de ser meros receptores pasivos; debemos dejar de ser informadores y aplicadores de exámenes para convertirnos en reguladores de la actividad de nuestros estudiantes. Tenemos que reflexionar que enseñar es insertar y orientar, con las técnicas apropiadas, el proceso de aprendizaje de nuestros alumnos para propiciar en ellos un sentido reflexivo apoyados por los medios, las técnicas y las actividades que hacen comprensible los contenidos específicos.

Por lo anterior es por lo que debemos procurar la profesionalización en la docencia, además del cambio de actitud y transformación que debemos estar dispuestos a aceptar si es que amamos nuestra labor como profesionales de la disciplina y la docencia.

¿Cuántos de los docentes de bibliotecología hemos logrado esa transformación pedagógica, psicológica, humana, y cuántos aún seguimos en la escuela tradicional?

La comunicación que se logre establecer en el salón de clases entre maestro y alumno es esencial, pues de ella depende que el alumno asimile de forma significativa las materias que se le imparten.

El plan de estudios de la licenciatura de bibliotecología está organizado por 49 materias que incluyen un total de 429 créditos distribuidos en seis líneas 
Flexibilidad curricular en la educación bibliotecológica

de formación, ${ }^{1}$ con 39 asignaturas teóricas y prácticas, 4 seminarios y 6 talleres.

Profesor y alumno deben propiciar la interacción grupal para facilitar la enseñanza y hacerla significativa a través de la comunicación que se establezca en el salón de clases y que fomente la reflexión sobre los contenidos escolares.

La formación bibliotecológica de la Facultad de Humanidades pretende insertarse en una educación eficiente, flexible y de alta calidad, e implicar conocimientos acerca de la realidad, local, regional, estatal y nacional, además de analizar las características económicas, políticas, sociales y culturales que les permitan a los alumnos abordar los retos y desafíos que habrán de presentársele al estudiante en proceso de formación.

El currículum de bibliotecología plantea nuevas propuestas respecto al proceso comunicativo entre maestro-alumno y propone un ámbito dinámico en el aula, donde el alumno enseñe su elaboración de ideas y la construcción de conocimientos que obtendrá del aprendizaje dado por el docente en un ambiente agradable.

1 1. Usuarios de la información, 2. servicios de información, 3. tecnología de la información, 4. organización de unidades de información, 5. investigación y 6. sistema de clasificación documental. 
El producto de esta particular interacción maestro-alumno es lo que le permitirá al alumno asimilar los conocimientos impartidos por el maestro.

El currículum de bibliotecología se basa en una propuesta constructivista, concebida a través del proceso enseñanza-aprendizaje, donde el alumno se apropiará de las estructuras de esta ciencia para ir transformando sus esquemas de conocimiento y poder interpretar su realidad.

En el currículum de bibliotecología el alumno es generador de su propio aprendizaje pero no en forma individual sino a través de la interacción docente-alumno, en la que este último tiene la oportunidad de relacionar los contenidos teóricos y la práctica social, con el propósito de ampliar su esquema de conocimientos y elevar su nivel cultural.

Para ello es importante que el docente conozca las características esenciales del grupo y que indague acerca de la relación social, ideológica y cultural que le ayude a posibilitar la creación de nuevas formas de trabajo grupales y de comunicación interactiva. ${ }^{2}$

2 El modelo dialógico de comunicación educativa busca la participación del alumno en el proceso educativo, corresponde a un modelo pedagógico que enfatiza el proceso de interacción entre las personas. Corresponde a un tipo de comunicación horizontal dialógico en donde el emisor y el receptor adquiere la flexibilidad en los papeles que desempeñan. 
Flexibilidad curricular en la educación bibliotecológica

Desde esta perspectiva, concibo nuestro papel como docentes dinámicos, creativos, capaces de crear un ambiente académico, social y emocional estimulante para que el alumno, al estructurar sus conocimientos, pueda expresar y enriquecer su estructura mental a través de la enseñanza recibida.

Los docentes y autoridades que participamos en la creación del currículo formal de bibliotecología $\mathrm{y}$ en los procesos de formación general del estudiante, vemos que el currículo incluye asignaturas encaminadas a dominar las herramientas informáticas y a usar los servicios de información. Ya que al mismo tiempo incluye en forma extracurricular otros elementos, como el manejo del idioma inglés, que constituye actualmente la base de los procesos comunicativos en la Internet, así como la promoción de valores que fomentan un compromiso ético con respecto a la difusión y de creación del conocimiento.

Por otro lado el cumplimiento de los propósitos curriculares y el alcance del perfil deseado, dependen en gran medida de la formación, actitud y concientización que se tenga acerca de la práctica docente antigua y la actual: la primera tiene que ver con el papel de profesor pasivo y tradicional; la segunda implica a un profesional, crítico y analítico, investigador de su propia práctica, una persona que cuenta con un alto nivel de conocimiento y estrate- 
gias didácticas que emplea dependiendo de los sujetos del aprendizaje, quienes tienen como claro propósito alcanzar lo delimitado por el currículo a fin de obtener una formación sólida para que puedan ejercer la profesión siguiendo las normas de la ética profesional en beneficio directo de los usuarios, de la comunidad a la que pertenece la institución prestadora de los servicios de información.

Ante este panorama la educación bibliotecológica tendrá que incorporar en sus programas de formación nuevos conceptos, principios, métodos y técnicas que le permita a sus profesionales generar propuestas y resolver problemas propios de esta sociedad contemporánea que se propone lograr la equidad y reducir la disparidad.

Las nuevas formas de organización curricular tendrán que ser adaptadas a diversas modalidades para permitirnos otras formas de integrar las asignaturas a los cursos: definir un tronco común, establecer etapas con propósitos de formación específicos y diversificar las etapas terminales (Núcleos de formación, Módulos, Proyectos, Problemas, Casos).

Nuestra responsabilidad como docentes en el proceso formativo del alumno de bibliotecología es mayor de lo que se piensa y sumamente importante, pues somos quienes finalmente seguimos o no los lineamientos curriculares establecidos en el plan de estudios. Esto se debe a que en la práctica el 
Flexibilidad curricular en la educación bibliotecológica

docente es autónomo al elegir y proporcionar los contenidos de acuerdo con la calidad de enseñanza que él mismo obtuvo.

Si logramos llevar a la práctica estas reflexiones, entonces sí nos estaríamos acercando a la construcción de un currículo flexible que toma en cuenta las políticas educativas de las IES (Institución de Educación Superior) en un contexto globalizado, en aras de mejorar la Educación bibliotecológica en Chiapas, en México y en América Latina. 


\title{
La flexibilidad curricular y la homologación de planes de estudio
}

\author{
ROSA MARÍA MARTÍNEZ RIDER
}

\section{Introducción}

Se plantean algunas reflexiones sobre la flexibili$\checkmark$ dad educativa en las universidades públicas para discutir sobre la homologación de los planes de estudio en las escuelas de Bibliotecología, Biblioteconomía, Archivología, Archivonomía y Ciencias de la Información del país.

Sobre la flexibilidad y homologación de los planes de estudio

La flexibilidad es parte de la postmodernidad, caracterizada por la globalización, la sociedad del conocimiento y las tecnologías de información y comunicación. Otros rasgos de esta época son el pensamiento relativista, "la ética del todo vale," la pluralidad que se disfraza en la neutralidad o la anarquía, el pragmatismo como forma de vida, la primacía de la estética sobre la ética, y los múltiples 
Flexibilidad curricular en la educación bibliotecológica

valores y antivalores que se cruzan originando confusiones, contradicciones y paradojas en los estudiantes. El daño al medio ambiente también genera gran angustia e incertidumbre en las nuevas generaciones

La denominada Sociedad del conocimiento, definida como "Aquella con pleno acceso y capacidad de utilización de la información y del conocimiento para su calidad de vida, el desarrollo individual y colectivo de los ciudadanos y para la gestión de la economía" hace patentes las desigualdades sociales en países como México, debido a los índices de analfabetismo en la lecto-escritura, el informacional, el digital, e incluso el escolarizado. ${ }^{2}$

La flexibilidad laboral surge de la autorregulación de la economía de mercado, y se refiere al tránsito del modelo fordista al de reconversión, que se desarrolla ampliamente con las nuevos modos de

1 K.Tapparanof, , "La sociedad del conocimiento: ¿un reto o una utopía para América Latina?, en: S. Córdoba González Contribución al desarrollo de la sociedad del conocimiento, México, UNAM, 2000, p. 7.

2 Alumnos que no pueden expresarse verbalmente ni por escrito, aun cuando se forman en una institución de educación. Profesores que tampoco tienen esas competencias y deforman al alumno. Los jóvenes han creado una nueva forma de escritura con el uso de la computadora. 
La flexibilidad curricular y la homologación de ...

comunicación y el uso de las TIC, junto con la idea de "la dimensión planetaria" de la CRESALC.

Se da paso a la descentralización y desconcentración de empresas y servicios con una nueva cultura de trabajo colaborativo, participativo y de ejecución eficiente. Sin embargo de la perspectiva económica se desprende una forma de flexibilidad académica como principio estructurante de "posiciones, diferencias ... identidades y sistemas de valores", ${ }^{3}$ y se plantean paradigmas alternativos para brindarle al estudiante una formación holística y socio-cultural, particularmente en las universidades públicas.

Diversos documentos nacionales e internacionales abordan aspectos conceptuales, ideológicos y prácticos de la flexibilidad, como los emanados de la UNESCO, la OCDE o el texto de Delors "La educación encierra un tesoro", así como los planteamientos del colombiano Mario Díaz Villa, Alicia de Alba, Bertha Orozco y Ángel Díaz Barriga, quienes identifican y analizan los principales problemas de México que tienen un impacto directo en la educación.

Lo más representativo de la flexibilidad educativa es el debilitamiento de los límites en los sistemas y las estructuras que la integran, que se dividen en

3 M. Díaz Villa, Nueva lectura sobre la flexibilidad, Santiago de Cali, 2000. p. 16. 
cuatro partes: la académica que se basa en "[...] un modelo organizativo más abierto, dinámico y polivalente que permita transformar las estructuras [...] rígidas y producir nuevas formas de organización mediadas por la interdisciplinariedad y el trabajo integrado" "4 la curricular se refiere a "[...] las formas de organización [...] las estructuras, áreas, asignaturas, componentes, ciclos o núcleos"; ${ }^{5}$ la pedagógica que "[...] genera nuevos significados, prácticas de interacción y formas de producción y reproducción del conocimiento"; por último, la administrativa se relaciona con "[...] el conjunto de procedimientos, normas y estilos de planeación, evaluación y gestión [...] de la institución", ${ }^{7}$ aquí es

4 M. Díaz Villa, Flexibilidad y educación superior en Colombia, Colombia, Instituto Colombiano para el Fomento y Desarrollo de la Educación Superior, 2002, pp. 104-105.

5 L. M. Nieto Caraveo, "La flexibilidad curricular en la educación superior", Conferencia magistral presentada en la XXXII Reunión Nacional de la Asociación Mexicana de Educación Agrícola Superior (AMEAS), 24 al 26 de octubre 2000, Tuxtla Gutiérrez, 2000, p. 10.

6 M. Díaz Villa, Flexibilidad y educación superior en Colombia, Bogotá, Instituto Colombiano para el Fomento y Desarrollo de la Educación Superior, 2002. p. 10.

7 L. M. Nieto Caraveo, "La flexibilidad curricular en la educación superior", Conferencia magistral presentada en la XXXII Reunión Nacional de la Asociación Mexicana de Educación Agrícola Superior (AMEAS), 24 al 26 de octubre 2000, Tuxtla Gutiérrez, 2000, p. 11. 
La flexibilidad curricular y la homologación de ...

donde se presentan más problemas, dada la rigidez de los sistemas educativos que llegan a entorpecer el desarrollo del proyecto curricular, porque todo está preestablecido y en ocasiones exageradamente controlado.

La flexibilidad curricular le permite al estudiante construir su propio currículum, de acuerdo con sus intereses académicos y sus expectativas laborales, además de los siguientes beneficios:

1. Tener un currículum integrado por proyectos, problemas y estudios de caso.

2. Desarrollar las competencias tanto del alumno como del profesor.

3. Contar con planes de estudio interdisciplinares organizados por regiones del conocimiento, aunque respetando los objetos de estudio de cada disciplina.

4. Tener planes de estudio diseñados por ciclos y créditos, y proporcionar opciones de formación.

5. Investigar paradigmas científico, simbólico y crítico.

6. Formar integralmente a los estudiantes.

7. Diversificar sus prácticas profesionales a partir del servicio social, y brindar alternativas de empleo.

La interrogante principal es: en un México tan contrastante y tan contradictorio ¿qué tipo de currículum se requiere diseñar considerando no sólo las variables locales y nacionales, sino las interna- 
Flexibilidad curricular en la educación bibliotecológica

cionales? Existen bibliotecas o archivos que no cuentan con ninguna computadora y en cambio otras que tienen tecnología de punta y grandes recursos financieros y humanos.

Es conveniente reflexionar y replantear algunos aspectos relacionados con las Ciencias de la Información, como la orientación epistemológica (los objetos de estudio y las relaciones entre las disciplinas), la ideológica (el papel político del profesional de la información en los proyectos de la derecha, la izquierda, la democracia, etcétera), la axiología y la ética en el currículum; el proyecto de hombre, mujer, ciudadano, bibliotecario, archivista, etcétera que se pretende formar; la sociedad del conocimiento a la que se aspira; y analizar lo local frente a lo global junto con las experiencias de aprendizaje que ayuden a apropiarse de la realidad.

La flexibilidad fomenta el trabajo colegiado y participativo, pero requiere dejar el pensamiento tradicional, dado históricamente, por ejemplo, cuando “[...]el profesor crea el sentido de propiedad privada de la materia [...] el sentido de las relaciones jerárquicas (de status) [...] y una práctica pedagógica aisla$\mathrm{da} "{ }^{\circ}$, pues el estudiante crea un "sentimiento de leal-

8 M. Díaz Villa, La formación de profesores en la educación superior colombiana. Bogotá, Instituto Colombiano para el Fomento de la Educación Superior, 200. pp. 22 
La flexibilidad curricular y la homologación de ...

tad obligada a la materia y un aprendizaje [...] descontextualizado, aislado, privado y competitivo, carente de toda disposición hacia la investigación o la crítica", ' de modo que se van generando problemas de desvinculación entre la teoría y la práctica. Lo más grave se refiere a que “[...]se valoriza más el trabajo de investigación que la formación profesional". ${ }^{10}$ Por lo tanto la flexibilidad no es fácil y se enfrenta a la resistencia y al rechazo, por lo que en las instituciones educativas se requiere de un sólido compromiso, buena actitud y un honesto deseo de cambiar las formas de relación existentes. Esto implica todo un proceso de modificación de las estructuras de pensamiento y sistémicas si se quiere lograr el éxito.

La homologación es un principio de flexibilidad, el cambio de los planes de estudio tiene como prioridad el diálogo, los acuerdos y los consensos entre las escuelas antes de modificar los planes de estudio. Esto facilita la aplicación de las mismas competencias en contextos diferentes, la movilidad estudiantil, el intercambio de profesores y los procesos de certificación o acreditación; y ayuda a la creación de redes académicas, la cooperación interinstitucional, el análisis y las propuestas de solución a proble-

9 Ibid.

10 Ibíd.p. 24. 
Flexibilidad curricular en la educación bibliotecológica

mas de aprendizaje comunes en las escuelas, y a la elaboración de textos para asignaturas comunes, entre otras cosas.

No obstante, homologar no es sinónimo de unificar o alinear, ya que los planes de estudio responden a necesidades sociales y del mercado de trabajo, a realidades concretas y específicas de cada región, las cuales tienen sus propios contextos, características y problemas. Además, las universidades públicas son autónomas para discutir libremente las ideas y proponer diferentes tipos de formación académica, aunque responden a diversos y diferentes agentes, agencias, discursos y prácticas profesionales.

\section{Conclusiones}

El panorama actual de los problemas sociales y del empleo en el mundo, hacen prioritaria la flexibilidad curricular para darle una mejor respuesta a la sociedad y ayudar a que los egresados de las escuelas tengan mayores oportunidades de inserción en el mercado laboral luego de hacer un seguimiento tutorial basado en un sistema de créditos que proporcione opciones de formación y de desarrollo de competencias variadas, tanto específicas como genéricas. 
La flexibilidad curricular y la homologación de ...

Ante los actuales cambios científicos, técnicos, tecnológicos, sociales, culturales, políticos y las necesidades de información de los usuarios, las escuelas que forman profesionales de la información tienen que definir los criterios que les permitan la homologación de sus planes de estudio para así diversificar las prácticas profesionales de los egresados. 


\title{
La formación del profesional de la información en la Escuela Interamericana de Bibliotecología
}

\author{
MARÍA Teresa MúNera TORReS
}

\begin{abstract}
G n la actualidad la Escuela Interamericana de Bibliotecología de la Universidad de Antioquia busca formar profesionales que puedan desempeñarse de manera idónea y cuenten con la suficiente solidez teórica para comprender y analizar los principios y características del ciclo de la transferencia de la información y de la información misma, además de que sean capaces de proponer soluciones a los problemas en el marco de la sociedad de la información y el conocimiento. También habrá que orientarlos en la comprensión del entorno que los rodea y en cuanto a las relaciones socio-culturales que debe establecer todo buen profesional de la información con espíritu de servicio, de tal forma que se proyecten como agentes interventores y dinamizadores en su contexto social. Se espera además que sean idóneos para caracterizar y tipificar las unidades de información, con base en su filosofía, vocación, área temática y desarrollo tecnológi-
\end{abstract}


Flexibilidad curricular en la educación bibliotecológica

co. Se los pone en contacto con las nuevas tecnologías de la información y la comunicación porque éstas son los componentes fundamentales del trabajo profesional bibliotecológico cuya aplicación es indispensable para estar en consonancia con las nuevas dinámicas de manejo de la información actual. Se los orienta en aspectos relacionados con la administración de unidades y sistemas de información como son las organizaciones de servicio, tras identificar las necesidades de información de los usuarios y la aplicación de técnicas de mercadeo, diseño y promoción de esos servicios.

Sin embargo, el reto que les plantea la nueva sociedad del siglo XXI a los profesionales de la información es inmenso, ya que las condiciones de su desempeño están enmarcadas por un nuevo paradigma. Si retomamos lo expresado por Susan Aramayo:

[...] puede decirse que casi todas las funciones tradicionales del bibliotecólogo de hoy han sufrido transformaciones $\mathrm{y}$, además han surgido desempeños nuevos. Los bibliotecólogos se pueden desempeñar como consultores, docentes que imparten cursos de formación y diseñan sistemas informáticos; con la aparición de la Internet se han convertido en expertos en búsquedas en la red, en webmasters y hasta en diseñadores de páginas web y de intranets. 
La formación del profesional de la información en la Escuela ...

De igual forma, retomando las reflexiones que hace Juan Manuel Pineda, se puede decir que en "la actualidad el perfil del profesional bibliotecológico ha evolucionado en consonancia con el desarrollo científico-técnico de la sociedad, su 'imagen' se ha transformado, ahora es un profesional de la información, y su nombre toma distintas denominaciones: bibliotecólogo, gestor de información, gestor de capital intelectual, infonomista, ingeniero de información y mediador de información entre otras acepciones". Por tanto, los nuevos bibliotecólogos tienen la responsabilidad de desempeñar su profesión de acuerdo con las demandas que les plantea la sociedad actual y de basarse en los códigos de ética y desempeño legal de la profesión.

En concordancia con lo ya anotado anteriormente es preciso destacar que la Escuela Interamericana de Bibliotecología, próxima a cumplir 50 años de existencia, es hoy una Unidad Académica fortalecida en los campos de la docencia, la investigación y la extensión. En cuanto a la docencia, la Escuela ofrece como programas de pregrado, el de Bibliotecología y el de Tecnología en Archivística. También el segundo semestre ofrece cursos de Especialización en Gerencia de Servicios de Información, y están en elaboración las propuestas de maestría en Ciencia de la Información así como la de la Especialización en Edición. Fuera de lo ante- 
Flexibilidad curricular en la educación bibliotecológica

rior, es importante resaltar la proyección de la Escuela en las Seccionales del Carmen de Viboral, Yarumal y Sonsón, mediante el desarrollo de la Tecnología en Archivística.

En cuanto a la investigación, nos es grato compartir el hecho de que la Revista Interamericana de Bibliotecología esté indexada en la categoría B de Conciencias y se proyecte como una de las revistas especializadas más importantes tanto de la Universidad de Antioquia, como de Iberoamérica. También nos da gran satisfacción contar con grupos de investigación clasificados en Conciencias, tales como el de biblioteca pública, clasificado en la categoría $\mathrm{A}, \mathrm{y}$ el de gestión del conocimiento, clasificado en la categoría B.

Además la Escuela cuenta con grupos de investigación que se espera sean reconocidos por Conciencias, en un futuro: el de Formación de Usuarios y el de Trabajo en Terminología.

Si se aprecia el panorama que proyecta hoy la Escuela desde sus programas de extensión, se puede evidenciar el posicionamiento que ha logrado mediante el exitoso desempeño de su Centro de Investigaciones en Ciencia de la Información CICINF y sus asesorías y consultorías en instituciones del orden público y privado. Cabe resaltar también el trabajo que ha venido desarrollando en cooperación con la Asociación de Egresados de la Escuela Inte- 
La formación del profesional de la información en la Escuela ...

ramericana de Bibliotecología de la Universidad de Antioquia, ASEIBI, de cuya unión se han beneficiado muchos de los profesionales de la Escuela.

En términos generales, la E.I.B., pretende formar profesionales que se caractericen por ser:

- Agentes promotores de cambio cultural y social que tienen una visión universal y capacidad para trabajar en equipos multiprofesionales e interdisciplinarios.

- Comunicadores con capacidad para interactuar con diferentes públicos.

- Gerentes de información con capacidad de gestión.

- Líderes en el manejo de la información y que cuentan con visión de futuro para decidir cuál, cuánto, cómo, cuándo almacenarla y a quién ofrecérsela.

- Promotores de productos y servicios tienen la habilidad para transferir la información.

- Creadores con capacidad de adaptar y apropiarse de procesos, y con una sólida comprensión acerca de los recursos de información y las tecnologías.

- Productores de conocimientos en los diversos campos de la formación y del ejercicio profesional.

- Educadores en la utilización adecuada de la información. 
Flexibilidad curricular en la educación bibliotecológica

\section{Campos de desempeño}

El bibliotecólogo está capacitado para desempeñarse en instituciones como bibliotecas académicas o universitarias; bibliotecas escolares; bibliotecas públicas; bibliotecas especializadas; bibliotecas infantiles; centros de documentación; librerías; ludotecas; centros de información empresarial; colecciones especiales; archivos de gestión; archivos históricos; instituciones culturales y bases de datos nacionales e internacionales.

En esos lugares puede desempeñar actividades relacionadas con:

- Planeación, gerencia y operación de unidades, redes y sistemas de información.

- Gestión de procesos sociales, científicos y culturales.

- Promoción de la lectura.

- Análisis de la información.

- Edición de libros y revistas.

- Formación de usuarios de la información.

- Historia y clasificación de las ciencias.

- Investigación y docencia .

- Gestión de archivos .

- Administración de redes de información y de bases de datos.

- Desarrollo de colecciones.

- Diseño, desarrollo y aplicación de tecnologías de la información. 
La formación del profesional de la información en la Escuela ...

- Gestión cultural.

- Medición y evaluación de colecciones.

- Mercadeo de servicios de información .

- Asesoría en búsqueda de información.

\section{Pregrado: Bibliotecología}

Estructura curricular actual de la Escuela Interamericana de Bibliotecología

En la actual estructura curricular el estudiante puede apropiarse de los principales saberes sobre la organización de la información, las tecnologías, la gerencia y su contextualización con base en la bibliotecología y la ciencia de la información, todo ello de una manera coherente y no secuencial sino sistémica, para lo cual se ha definido la siguiente estructura:

Estructura curricular actual de la E.I.B.

\begin{tabular}{||l|l|l|l||}
\hline \multicolumn{4}{|c||}{ Ejes Metodológicos } \\
\hline Investigación & Servicio & Gestión & Integración \\
\hline
\end{tabular}

\begin{tabular}{||l|l|l||}
\hline \multicolumn{3}{|c||}{ Etapas Curriculares } \\
\hline Inmersión & Profundización & Consolidación \\
(Semestres 1 y 2) & (Semestres 3-6) & (Semestres 7 y 8) \\
\hline
\end{tabular}


Flexibilidad curricular en la educación bibliotecológica

\begin{tabular}{||l|l|l|l|l||}
\hline \multicolumn{5}{|c||}{ Mesoestructura: Núcleos Temáticos y Problematizadores } \\
\hline $\begin{array}{l}\text { Contextualización } \\
\text { de la información } \\
\text { (Inmersión) }\end{array}$ & $\begin{array}{l}\text { Caracterización de } \\
\text { la información } \\
\text { (Inmersión) }\end{array}$ & $\begin{array}{l}\text { Organización de } \\
\text { la información } \\
\text { (Profundización) }\end{array}$ & $\begin{array}{l}\text { Tecnologías de } \\
\text { la información } \\
\text { (Profundización) }\end{array}$ & $\begin{array}{l}\text { Gerencia de la } \\
\text { información } \\
\text { (Consolidación) }\end{array}$ \\
\hline \hline
\end{tabular}

\begin{tabular}{||l|l||}
\hline \multicolumn{2}{|c|}{ Macroestructura: Campos del Conocimiento } \\
\hline Profesionalizante & Formativo general \\
\hline
\end{tabular}

\begin{tabular}{||c||}
\hline \multicolumn{1}{|c|}{ Microestructura } \\
\hline Asignaturas integradas \\
\hline
\end{tabular}

\section{Bibliografía}

Centro de Interés Profesional, Paola Andrea Ramírez Pérez, Medellín, Escuela Interamericana de Bibliotecología, 2005.

http://bibiliotecologia.udea.edu.co/andrear/centrointeres/bperil.html

"La Labor Profesional de Bibliotecarios y documentalistas en el Siglo XXI”, Susan Aramayo, en Bid, Núm. 6 (jun. 2001).

Mensaje a Graduandos 2006, María Teresa Múnera Torres, Medellín, Universidad de Antioquia, Escuela Interamericana de Bibliotecología, 2006. 
La formación del profesional de la información en la Escuela ...

El Nuevo Perfil Profesional del Bibliotecario de Cara al Nuevo Milenio, Juan Manuel Pineda, en: http:// juanmanuelpineda.tripod.com/perfil.html

Proyecto Educativo Institucional, Universidad de Antioquia, Escuela Interamericana de Bibliotecología, Medellín, La Universidad, 2003, 37 p. 


\section{Discusión}

Oon base en los documentos preparados
previamente, los participantes del Seminario
Virtual de Educación Bibliotecológica discutieron
en el Foro Académico sobre la flexibilidad curricu-
lar, partiendo de que una de las críticas más impor-
tantes que se ha hecho a los planes de estudio en bi-
bliotecología ha sido la rigidez académica con que
se han diseñado éstos. Está estructura rígida es un
obstáculo que vale la pena discutir, en virtud de los
retos que implica la internacionalización de la edu-
cación y el fortalecimiento de la enseñanza de la
profesión en cada uno de los países de la región ibe-
roamericana. Sin embargo este problema se enfren-
ta de modo diferente en cada país, y por lo tanto
asume rasgos particulares e implica desarrollar es-
trategias de planeación curricular ad hoc. El espacio
de reflexión conjunta es indispensable para identifi-
car cómo se ha delimitado la necesidad de flexibili-
zación o bien cómo conviene hacerlo, y para socia-
lizar la experiencia acumulada por las diferentes
escuelas de bibliotecología. Por lo anterior y con el
objetivo expreso de iniciar este importante debate e


Flexibilidad curricular en la educación bibliotecológica

intercambio de experiencias, se plantearon las siguientes preguntas de trabajo:

a) ¿Qué entendemos por flexibilidad curricular?

b) ¿Cuáles son los problemas que implica la flexibilización de los planes de estudio en bibliotecología y cuáles son las estrategias que se han seguido?

c) ¿Qué ventajas ha reportado su instrumentación?

d) ¿Qué utilidad tendrá la flexibilidad para el futuro de la educación bibliotecológica para los países iberoamericanos?

En términos generales la flexibilidad curricular se refiere a la movilidad interna y externa de un currículo, es decir, de un plan de estudios. Esta flexibilidad se da con la interdisciplinariedad, la integración, las competencias profesionales y los sistemas de créditos, entre otras cosas. Así, la flexibilidad plantea una diversidad de opciones de educación que pretende alcanzar un nivel equitativo de competencias educativas. La flexibilidad es un elemento básico que coadyuva a la Sociedad del Conocimiento para romper las estructuras de tiempo y espacio en aras de adquirir un conocimiento que transforme las relaciones sociales de aprendizaje, a partir del redimensionamiento de las prácticas pedagógicas, ya que no es necesario compartir un espacio físico para compartir un conocimiento ni tampoco tener una relación sincrónica. 
De esta forma, la flexibilidad curricular implica abrir los espacios rígidos, coordinados por normas y reglas institucionales, para darle paso a una formación profesional en la que el actor principal es el alumno y sus intereses profesionales. Cabe mencionar que según Romero, la única finalidad de esto es abrir los procesos de enseñanza-aprendizaje cuyas características son: a) que persigue permanentemente los nuevos conocimientos que plantean los procesos de formación; b) promover la capacidad de decisión en el alumno, para que pueda elegir los créditos que debe cursar, c) propiciar la comunicación horizontal y vertical de los contenidos; d) optar por el aprendizaje integral mediante el contacto con el mundo circundante, e) vincular a la universidad con distintas instituciones de la sociedad, y f) estimular la interdisciplinariedad.

La flexibilidad implica buscar una mayor articulación o integración de las unidades y agentes responsables de la dirección y la gestión de todos estos procesos. En este sentido exige también acciones de concertación política y académica alrededor de compromisos establecidos a la vez que tareas de innovación y cambio de propuestas. La noción de flexibilidad curricular o de currículo flexible se ha ido convirtiendo en una herramienta metodológica que le otorga un nuevo sentido a los diferentes aspectos que plantean las reformas académicas en la educa- 
Flexibilidad curricular en la educación bibliotecológica

ción superior. Desde este punto de vista, la noción de flexibilidad curricular se asocia, como marco general, a reformas de la educación superior en aspectos tales como la reorganización académica; el rediseño de programas académicos y de sus planes de estudio; la transformación de los modelos de formación tradicional; la redefinición del tiempo de formación; una mayor asociación de la formación con las demandas del entorno laboral, etcétera. $\mathrm{Al}$ abordar la flexibilidad curricular en su dimensión estructural, se plantean dos tipos de estrategias: a) unas centradas en modificar los patrones organizativos del conocimiento; esto es, en abrir los límites entre campos, áreas y unidades de conocimiento que conforman el currículo, de modelos curriculares organizados con base en disciplinas, a modelos curriculares más integrados, y b) otras que buscan la ampliación y diversificación de la oferta educativa para satisfacer mejor las demandas sociales y los intereses del estudiante, brindándoles mayores grados de autonomía en la organización de su programa de estudios. En ambas modalidades, la flexibilidad implica una reconceptualización de las formas tradicionales y una mayor articulación de los conocimientos que se producen y trasmiten, con los intereses estudiantiles $\mathrm{y}$ con las demandas del entorno social.

En la Sociedad de la Información y el Conocimiento, la educación bibliotecológica requiere pla- 
nes de estudio flexibles que respondan a las necesidades de dicha sociedad en cuanto a interdisciplinariedad, diversas competencias, nuevas formas de evaluación, etcétera. Por esta razón, con frecuencia surgen diversos problemas que se derivan del concepto mismo de flexibilidad, cuando por ejemplo se asocia sólo al mercado, y se pierde de vista la formación humanística de los recursos financieros, humanos y materiales, así como de las estructuras administrativas porque involucran aspectos jurídicos y normativos a los que deben ajustarse todas las entidades de una institución educativa. Otros problemas se relacionan con los nuevos modelos educativos y pedagógicos, por ejemplo, el uso de las TIC's (Tecnologías de la Información y la Comunicación).

Pese a los problemas que pudieran presentarse en la instrumentación de un currículo flexible, se identifican ventajas que hacen que organismos internacionales consideren a la flexibilidad como un aspecto básico del diseño curricular. La principal ventaja de un currículo flexible es que el alumno está en condiciones de construir su propio plan de estudios pensando en sus intereses y necesidades de formación, lo cual reduce su carga horaria frente al grupo y organiza mejor su tiempo y sus actividades. Esto le brinda mayores oportunidades de diversificación profesional y de empleo, y además contribuye a mejores discusiones académicas, una 
Flexibilidad curricular en la educación bibliotecológica

homologación de planes de estudio, mayor movilidad estudiantil, el intercambio de profesores, la cooperación interinstitucional y la creación de redes académicas nacionales e internacionales con objetivos comunes.

En México, al preguntarnos que tipo de currículo requiere nuestra profesión en un país tan contrastante y contradictorio, nos damos cuenta que debemos formar profesionales que posean una actitud creativa, constructiva y reflexiva sobre los problemas y fenómenos que aquejan a nuestra profesión, independientemente de como se llamen las asignaturas que cursen; lo más importante es enseñarles aspectos teóricos que fundamenten sus conocimientos prácticos y los capaciten para desempeñar los diferentes procesos y actividades que requiere una biblioteca o centro de información. Además, deben aprender a resolver los diferentes problemas que se presentan y a tomar decisiones que ayuden a mejorar nuestra profesión y nuestras instituciones. Deberán tener claro aquellos conocimientos, valores y habilidades que caracterizan a nuestra profesión.

He aquí un ejemplo de la aplicación de planes de estudios flexibles:

Para proporcionar a los docentes de la Universidad Juárez Autónoma de Tabasco (UJAT) los elementos teóricos, metodológicos y operativos que les permitan contribuir en el fortaleci- 
miento del Programa de Flexibilidad Curricular, la Dirección de Estudios y Servicios Educativos (DESE), llevó a cabo el curso 'Currículum basado en competencias'. El curso realizado en la sala de usos múltiples del Centro de Cómputo Universitario fue impartido por Concepción Barrón Tirado, doctora en Pedagogía con mención honorífica por la Facultad de Filosofía y Letras de la Universidad Nacional Autónoma de México (UNAM) a los profesores que integran las Comisiones de Revisión Curricular en las 9 divisiones académicas y la Extensión Universitaria de los Ríos. Cabe mencionar, que el Programa de Flexibilidad Curricular de la UJAT, forma parte del programa de trabajo 2000-2004 de la actual administración.

(http://www.ujat.mx/noticias/765/flexibilidad.html).

Para Alice Miranda, la flexibilidad en la educación superior se puede analizar desde dos perspectivas geográficas: la de la Unión Europea y la de América Latina. La Declaración de Boloña (European Higher Education Area. Joint Declaration of the European Ministers of Education convened in Bologna on 19 June 1999) que fue firmada por 31 representantes de 29 estados miembros y estados candidatos de la Unión Europea, es clara y concreta. La Declaración propone que para el 2010 logrará una educación superior inclusiva basada en las siguientes metas: 1 . Un sistema de fácil lectura y una 
Flexibilidad curricular en la educación bibliotecológica

titulación homogénea, además de un diploma adicional. 2. Un sistema de cursos consecutivos que le permita al alumno obtener un pregrado (3 años) para que pueda optar por un empleo, y un grado académico que puede ser de maestría o doctorado. 3. Le asegura a los estudiantes flexibilidad en la transferencia de sus calificaciones a cualquier país de los que firmaron la Declaración. Para ello se tiene que contar con un sistema de créditos internacional, lo que implica el otorgamiento de créditos a cualquier curso que se ofrezca como actualización permanente. 4. La promoción de flexibilidad y movilidad para los estudiantes. 5 . El establecimiento de un programa de aseguramiento de calidad cooperativo europeo. 6. La dimensión educativa europea se promoverá con énfasis en los currículos de la educación superior, para que existan esquemas de cooperación y de movilidad inter-institucional tanto para estudiantes como para profesores/investigadores (Declaración de Boloña).

La concepción latinoamericana aborda los mismos postulados pero agrega matices locales. Se argumenta que para alcanzar la flexibilidad curricular se deben tomar en consideración los factores sobre los que se va a intervenir. Guerra, Pabón y Restrepo señalan como aspectos fundamentales por resolver: a) la exclusión social, b) la falta de equidad, c) el fomento de las condiciones para la permanencia en 
la educación superior, en especial para los sectores más desprotegidos y d) la formación holística.

a) En cuanto a la exclusión social histórica el principal elemento es el poder adquisitivo: a mayores recursos económicos mejores oportunidades para acceder a una educación media de calidad y, como consecuencia, una garantía para asegurarse un espacio permanente en aquellas universidades reconocidas por su calidad, a lo largo de la vida, ya sea para una titulación o una educación continua, lo cual provoca una desigualdad para quienes no pueden pagar para matricularse y cursar el plan de estudios en universidades prestigiosas; o quienes en un alto número de casos, no han recibido la capacitación que hace falta para concursar por espacios de ingreso.

b). La falta de equidad es consecuencia de la carencia de políticas y programas nacionales que le garanticen a la población que ingresa a la educación superior las oportunidades que le puede brindar; sin embargo habrá de cuidarse que no se amplíe la brecha entre los que tienen y los que no tienen, sino en consolidar un "alto nivel de confianza en la capacidad de aprendizaje de todas las personas".

c).Habrá que fomentar las condiciones para que la educación superior le permita al estudiante utilizar ese aprendizaje como estrategia universal en 
Flexibilidad curricular en la educación bibliotecológica

diferentes espacios y ambientes de la vida; habrá que formarlo para aprender $y$ desaprender y proporcionarle competencias para la movilidad, el cambio y la multifuncionalidad, lo cual sólo puede garantizarlo una actitud de aprendizaje durante toda la vida y el dominio de competencias específicas.

d). La formación holística contribuye a formar ciudadanos más integrales y sociedades más éticas, solidarias, democráticas y justas.

\section{Cuestionamientos}

A ¿Qué entendemos por flexibilidad curricular? Flexibilidad curricular significa visión, consensos, cambios, redes de comunicación y compromiso con la excelencia, así como respuestas al caos educativo ocasionado por la carencia de políticas y sistemas coherentes en lugar de un espíritu internacional que facilite la homologación y el libre ejercicio de las profesiones a nivel global. Un mundo más equitativo y solidario es el resultado de un sistema educativo menos complejo, rígido y abstracto.

B. ¿Cuáles son los problemas que implican la flexibilización de los planes de estudio en bibliotecología y cuáles las estrategias que se han seguido? La flexibilización de los planes de estudio no es un acto voluntario hace una unidad académica, 
una disciplina o una persona, se trata de un engranaje institucional que implica una gran cantidad de acciones relacionadas con todos los entes involucrados con el desarrollo de un currículo. En algunas ocasiones esos esfuerzos son tan desgastantes e infructuosos que desmotivan a un colectivo que se esfuerza para modificar o ampliar la oferta académica. El temor al cambio es un factor que interviene en el mantenimiento de la rigidez académica. Los espacios de reflexión conjunta son muchas veces escasos y poco aprovechados para generar análisis y motivación que dinamicen los currículos. La principal estrategia para enfrentar este asunto es el liderazgo académico y la constante intervención en foros y eventos donde se ventilen estos temas.

C. ¿QQué ventajas ha reportado su instrumentalización? En la Universidad Nacional de Costa Rica, la instrumentalización de la flexibilidad curricular se realizó de manera complementaria a dos procesos: a) la reforma académica universitaria y b) el rediseño de los planes de estudio. Estos dos grandes procesos permitieron modificar e introducir una serie de variantes que mejoraron el plan de estudios y permitieron enfrentar mejor los paradigmas de la globalización y de las últimas Tecnologías de la Información y comunicación (TIC's) desde los cursos iniciales. En algunos casos esto fue producto 
Flexibilidad curricular en la educación bibliotecológica

de la solicitud e intervención de los estudiantes, graduados, académicos y empleadores; en otros fue el resultado de la participación en foros de discusión y reuniones de especialistas. Dentro de las ventajas obtenidas están: 1 . La adecuación de los contenidos curriculares y la inclusión de los ejes transversales de la institución (género, ética, equidad, desarrollo sostenible, diversidad cultural, ambiente y cultura ambiental). 2. El tema información como elemento básico para construir el conocimiento y como parámetro de auditoria al definir estrategias de gestión. 3. Incorporación de la Ley 7600 sobre igualdad de oportunidades para los estudiantes con necesidades educativas especiales. 4. La determinación de capacitar a los estudiantes en el manejo del idioma inglés como parte integral del plan de estudios. 5. Incorporación de cursos de elección del estudiante (entre 8\% y 15\%). 6. Inclusión de ejes curriculares en la especialidad Gestión de unidades de información documental, Tecnologías de la información y comunicación y Métodos y técnicas de investigación. 7. Definición de las áreas disciplinarias de la Escuela: Organización de la Información Documental, Investigación, Lectores/Usuarios/ Clientes, y Administración de Recursos y Servicios de Información. 8. Reafirmar en el plan de estudios que el quehacer de la bibliotecología y la documentación es interdisciplinario y de 
servicio para otras disciplinas. 9. La diversificación del plan de estudios: un pregrado como tronco común y a nivel de bachillerato dos énfasis (Gestión de la Información y Tecnologías de la Información y comunicación). 10. Se optó por una metodología pedagógica innovadora, activa y experimental, donde los papeles del estudiante y el académico se interrelacionen. 11. Se privilegian los cursos teórico-prácticos para facilitarle al estudiante la oportunidad de desempeñarse en un espacio laboral real.

D. ¿Qué utilidad tendrá la flexibilidad curricular para el futuro de la educación bibliotecológica en los países iberoamericanos? El futuro es prometedor y está ahí para asumir actitudes positivas y trabajar con relevancia. Entre las utilidades para los países iberoamericanos están: que el profesor se convierte en un guía, un mentor, un mediador, para que el estudiante asuma el papel protagónico, construya conocimiento y sea responsable de su aprendizaje. El plan de estudios provocará el análisis crítico en el estudiante a partir de la elaboración de investigaciones, la aplicación de paquetes tecnológicos y la utilización de la telemática para organizar, recuperar y transferir la información; a esto hay que añadir las prácticas en las unidades de información documental. Se privilegiará el estudio, la investigación y la resolución de problemas con el apoyo y 
Flexibilidad curricular en la educación bibliotecológica

la manipulación de paquetes tecnológicos que facilitan la gestión de la información y las prácticas en unidades de información documental. Se propiciará la integración del estudiante en el mercado laboral al favorecer la realización de prácticas e investigaciones en el campo profesional de las bibliotecas, museos, archivos y cualquier otra entidad que administre información y retroalimentación a las aulas. El estudiante se formará para pensar, discutir, crear, trabajar en equipos, esclarecer puntos de vista, compartir y resolver problemas reales en ambientes laborales. Se promoverá una visión integral en los trabajos de investigación individual, grupal, o en la resolución de problemas y en la problematización de contenidos, para lo cual se usarán metodologías activas y experimentales para que los profesionales enfrenten los cambios significativos que el trabajo informacional requiere en esta época. Los estudiantes realizarán investigaciones que les permitan desarrollar teorías para aplicarlas en sus actividades prácticas en las unidades de información documental y en los laboratorios de computación, a través de la utilización de paquetes tecnológicos y de la telemática para el procesamiento, recuperación y transferencia de información, para ello aportarán trabajos netamente interdisciplinarios que el especialista de la infor- 
Discusión

mación compartirá continuamente con otros profesionales de diferentes disciplinas. Se requerirá la evaluación continua y permanente del plan de estudios de la carrera, entendiendo la evaluación como un proceso de análisis que identifique todos los factores que contribuyen, directa o indirectamente, a la optimización en su concepción, ejecución y prospección. Los cursos serán evaluados por los académicos de cada área implicada en forma anual. Se aplicarán variables definidas, se llevarán a cabo las estrategias de cambio, las de nuevas modalidades, las de nuevas tecnologías y las de nuevas metodologías Los estudiantes participarán con sus opiniones o con sus sugerencias a través de informes.

De forma más precisa y dado que la flexibilidad curricular implica consenso, negociación, trabajo en equipo, intercambio académico, ampliación de horizontes, desarrollo de proyectos conjuntos, apertura hacia el diálogo permanente interdisciplinario, en la Escuela de Bibliotecología, Documentación e Información de la Universidad Nacional de Costa Rica se ha estado trabajando desde 1997 hacia la flexibilidad curricular en el marco del proyecto de reforma académica que realizó la Universidad. Para iniciar tal acercamiento a esa flexibilidad curricular se han tenido que aceptar varias condicionantes logísticas y académicas, tales como: 
Flexibilidad curricular en la educación bibliotecológica

- Horizontalidad del plan de estudios. Esto significó aceptar que los estudiantes no matriculen de manera obligatoria los cursos de humanidades (estudios generales y propedéuticos) antes de ingresar a la Carrera.

- Requisitos y correquisitos. Eliminar lo más posible los requisitos de cursos previos para matricular cursos de otros niveles y en todo lo posible eliminar correquisitos.

- Bloques completos. Permitir que los estudiantes matriculen el número de cursos que puedan o quieran por semestre y que se gradúen con el ritmo de trabajo que ellos escojan.

- Cursos optativos. Aceptar que entre un $8 \%$ y un $10 \%$ de los créditos de la Carrera, sean escogidos por los estudiantes dentro de la oferta de cursos optativos que la Universidad pone a disposición de los estudiantes cada periodo lectivo. En reuniones de estudiantes que se convocan para hablarles al respecto, se les sugiere la conveniencia de que matriculen los cursos en una misma área temática, por ejemplo, si trabajan o piensan trabajar en una unidad de información documental del área de ciencias exactas, sería ideal llevar cursos de ese campo del saber.

- Equiparación y equivalencia de cursos. Equiparar materias o títulos de otras universidades y equivaler cursos de otras carreras incluso sin que 
reúnan el 100\% de los contenidos curriculares y, en algunas ocasiones, dependiendo esto del dictamen de la Comisión de Diseño Curricular, con lo que podrán no contar con el mismo número de créditos, el mismo número de horas de dedicación al curso y bibliografías similares.

- Diseño del plan de estudios. Debe existir un plan de estudio aprobado por la Escuela, la Facultad, la Universidad y CONARE (Consejo Nacional de Rectores). Este plan de estudios debe incluir como mínimo: justificación, antecedentes de la carrera, áreas disciplinarias, ejes curriculares y transversales, opción metodológica, perfil ocupacional, perfil profesional, objetivos de la carrera, metas de formación, permanencia de los estudiantes en la carrera, malla curricular, estructura de los cursos, cursos con requisitos, correquisitos y tipo de laboratorio; así como descripción de los cursos, tabla de equivalencias, bibliografía y anexos. La escuela al seleccionar las áreas disciplinarias y los ejes curriculares y transversales se compromete a trabajar desde esa perspectiva la dimensión de docencia, investigación, extensión y producción. Es importante que al reflexionar sobre la flexibilidad curricular se tenga presente que debe existir apertura al diálogo institucional, nacional, regional y global. Además de que el profesional egresado que se requiere es alguien 
Flexibilidad curricular en la educación bibliotecológica

que sea capaz de aceptar su profesión para dimensionarla y liderar en un mundo globalizado en el que rige un mercado común que requiere profesionales integrales que puedan organizar la información, acceder a ella y ponerla oportunamente a disposición del consumidor.

Finalmente, en la Unión Europea la flexibilidad curricular se fomenta para lograr un currículo internacional que permita la movilidad laboral y estudiantil en el seno de la región y con perspectivas globales.

Por otra parte, en España el campo de la Biblioteconomía y Documentación ha apostado seriamente por un programa que reúna los esfuerzos de la mayoría de las universidades españolas para enfrentar esa realidad que se llama Espacio Europeo de Educación Superior (EEES). El documento "La Unión Europea lleva años trabajando en la creación de un espacio europeo de educación superior que culminará en el año 2010" pretende una convergencia universitaria que facilite una mayor compatibilidad de las titulaciones entre las universidades europeas. En este sentido la Declaración de Bolonia fijaba como objetivos: La adopción de un sistema de titulaciones fácilmente comprensible y comparable que contemple el desarrollo de un suplemento al título; la introducción de un sistema 
basado en dos ciclos: uno de grado de una duración mínima de tres años y uno de postgrado; la implantación de un sistema de créditos común; la promoción de la movilidad de los estudiantes, del profesorado, de los investigadores y del personal de administración mediante medidas adecuadas de reconocimiento; el impulso de la cooperación europea en el establecimiento de medidas que aseguren la calidad de la formación.

La promoción de la dimensión europea de la educación superior con la finalidad de alcanzar acuerdos en aspectos como el desarrollo curricular, la cooperación interinstitucional, y los programas integrados de estudio, formación e investigación en la Agencia Nacional de Evaluación de la Calidad y Acreditación (ANECA), publicó una primera convocatoria de ayudas para el diseño de planes de estudio y títulos de grado adaptados al Espacio Europeo de Educación Superior (EEES). En este marco se ha realizado el Proyecto sobre el título de grado en Información y Documentación que integrará a las actuales titulaciones de diplomatura en Biblioteconomía y Documentación y de licenciatura de segundo ciclo en Documentación. En este proyecto, coordinado por la Universitat de Barcelona y en concreto por Assumpció Estivill, decana de la Facultad de Biblioteconomía y Documentación, han participado las facultades y escuelas de Biblioteco- 
Flexibilidad curricular en la educación bibliotecológica

nomía y Documentación de catorce universidades españolas: Universidad Autónoma de Barcelona, Universidad de León, Universidad Carlos III, Universidad de Murcia, Universidad Complutense de Madrid, Universidad de Salamanca, Universidad de Alcalá, Universidad de Valencia, Universidad de Barcelona, Universidad de Vic, Universidad de Extremadura, Universidad de Zaragoza, Universidad de Granada, Universidad Politécnica de Valencia, Universidad La Coruña y Universidad Oberta de Catalunya. Además de las propias universidades han participado las asociaciones profesionales y otros colectivos implicados, como empleadores y titulados. Recientemente, este proyecto ha sido evaluado por la ANECA de forma muy positiva y publicado como libro blanco, y fue remitido a la Dirección General de Universidades (MECD) y al Consejo de Coordinación Universitaria para su consideración en el posterior desarrollo normativo. De este texto hemos de deducir lo siguiente:

1.- Todas las partes estaban implicadas. Universidades (Profesores, alumnos en curso y alumnos que ya habían finalizado). Profesionales con varios años de trabajo y los recién incorporados. Instituciones del ámbito de la documentación.

2.- Había consenso en los resultados. Hasta definir el nombre fue una lucha, pero gracias a la labor de los coordinadores y, sobre todo, al consenso de 
todos, el proyecto salió adelante. Actualmente se habla del título de Grado en Información y Documentación, de tal forma que la Biblioteconomía (bibliotecología) desaparece del nombre de la carrera.

3.- Existen las ganas de avanzar y adaptar los estudios a una nueva sociedad. Los profesionistas demandan un tipo de formación que les permita encontrar trabajo con más facilidad y mejor remunerado. En definitiva la flexibilidad curricular ha de iniciarse cuando se creen los estudios de cualquier área temática; y posteriormente habrá que adaptarlos a las demandas de la sociedad y tratar de no ir por un camino distinto al que los alumnos desean.

En cuanto a los problemas que implica la implementación de currículos flexibles, Elsa Barber menciona que en América Latina, una de las estructuras más empleadas hoy por las universidades y que se evalúa según las necesidades de movilidad es el ciclo, que tiene una duración variable de acuerdo con los propósitos educativos que se fijen en cada caso. Como estos periodos de enseñanza estructuran las titulaciones, la culminación del ciclo se acredita a través de un certificado o diploma que tiene una denominación básica común. En la universidad latinoamericana la estructura de ciclos tiene una larga trayectoria que ha buscado contrarrestar la excesiva 
Flexibilidad curricular en la educación bibliotecológica

profesionalización de la formación de grado; no obstante hoy parece revitalizarse en un sentido más amplio de articulación no sólo al interior de cada carre$\mathrm{ra}$, sino entre aquellas carreras que comparten un mismo campo de conocimiento. Ahora bien, específicamente, la Universidad de Buenos Aires, en el marco del Acuerdo de Gobierno para la Reforma de la Universidad del año 1995, estableció una reestructura curricular general de las formaciones de grado y posgrado. A nivel del grado se concibieron los siguientes ciclos: Los Estudios Generales correspondientes al Primer Ciclo se plantean con el propósito de "iniciar a los estudiantes en el empleo de operaciones cognitivas complejas y de estrategias útiles para diversas formas de producción, en particular, la científica", pero tienen, además, un propósito orientador o reorientador en relación con la decisión vocacional. Los Estudios Básicos, buscan brindar la formación básica requerida para las carreras de grado de la universidad acordando los conocimientos fundamentales indispensables para aprendizajes posteriores. El Segundo Ciclo o Ciclo de Estudios Orientados consta de un conjunto de asignaturas que completan la formación previa del alumno en la orientación elegida, y debe (acentuar) la especificidad de la orientación sin perder de vista que la multidisciplinariedad es un requisito para todas las carreras y que por lo tanto tampoco se debería 
intensificar exageradamente esa especialización. En tal sentido, el Acuerdo general plantea evitar la "[...]exposición prematura a contenidos especializados que no se habrán de emplear sino mucho más tarde en la carrera..." . .] El Tercer Ciclo o Ciclo Profesional o Académico está destinado, en la mayoría de las carreras, a brindar la formación que permite otorgar un título de grado académico o habilitación para el trabajo y la formación científica necesario para quien se dedique a la investigación, la docencia y el desarrollo profesional. Una propuesta de reorganización estructural curricular de esta envergadura se fundamenta, en el caso de la UBA, en los logros ya alcanzados en materia de flexibilidad de los planes de grado y la existencia previa de estructuras curriculares similares al ciclo, tales como: un primer $\mathrm{Ci}$ clo diferenciado (Ciclo Básico Común); algunas carreras largas con títulos intermedios y otras con una diferenciación virtual o explícita en el plan de estudios, entre ciclos sucesivos; algunas carreras largas sin título intermedio, pero con diferenciación en ciclos de formación (Ciclo general y Ciclo de formación profesional; Ciclo general y Ciclo orientado, etcétera); algunas carreras largas, sin título intermedio, pero con demanda en el mercado de trabajo de estudiantes más o menos avanzados en la carrera; y algunas carreras cortas que otorgan un certificado de la Facultad o un Diploma de la Universidad. Te- 
Flexibilidad curricular en la educación bibliotecológica

niendo en cuenta todas estas premisas el plan vigente de bibliotecología en la Universidad de Buenos Aires es flexible y está conformado en ciclos, con orientaciones que el estudiante puede ir armando a su medida. Además algunas materias las debe cursar en otras carreras de la misma universidad. La mayor dificultad radica en la ausencia de articulación instituida formalmente entre carreras cortas y largas, y en los requerimientos de reorganización académica que una iniciativa de esta naturaleza supone para una macro universidad pública.

Todo lo anterior le ha reportado algunas ventajas a la educación superior en Argentina, como: a) Promover experiencias de integración de los contenidos formativos en dos dimensiones: entre disciplinas y entre funciones universitarias. Entre disciplinas: impulsar estrategias centradas en modificar los patrones organizativos del conocimiento; esto es, de apertura de los límites entre campos, áreas y unidades de conocimiento que conforman el currículo, apuntando a la flexibilización de los modelos disciplinares y a la experimentación de modelos más integrados. Y entre funciones: impulsando estrategias centradas en modificar las formas de articulación enseñanza-extensión-investigación en la enseñanza de grado a través de la creación de "espacios” curriculares creados para tal fin. b) Pero también se incrementa la opcionalidad al interior de 
cada carrera (materias optativas) y se acotan los regímenes de correlatividades a criterios epistemológicos, eliminando prerrequisitos prescindibles. Entre carreras: c) incrementa la opcionalidad entre las carreras (materias electivas); esto es, la posibilidad de elegir en un trayecto de formación materias correspondientes a otras carreras, de acuerdo con el interés personal del estudiante; d) integra contenidos a través de materias compartidas por dos o más carreras; e) concibe carreras compartidas entre áreas de conocimiento afines; f) articula las carreras cortas con las carreras largas; g) unifica las entradas a la formación de grado por medio de la organización de troncos comunes entre carreras y establece asignaturas obligatorias, así como opcionales, vinculadas a las orientaciones que se sigan posteriormente. En el nivel de Áreas: h) unifica las entradas a la formación por medio de la creación de troncos comunes por Áreas que pudieran conjugar asignaturas comunes y diversificadas, por orientación (materias obligatorias, materias optativas).

Sin embargo es necesario pensar en un currículo flexible a nivel regional y general en tanto que la flexibilidad académica debe partir de un enfoque basado en procesos de calidad que les permita movilidad a los actores de la universidad en cuanto a la generación de conocimiento y la socialización resultantes de la vinculación con la investiga- 
Flexibilidad curricular en la educación bibliotecológica

ción. Pero surge nuevamente la pregunta: ¿qué tipo de curriículum se requiere diseñar? Tomando en cuenta la dimensión académica, la bibliotecología necesita un programa y un currículum diseñado en tres aspectos que se vislumbran desde el ejercicio diario:

1. Enfatizar las áreas básicas y de especialidad, proporcionando conocimientos útiles y específicos acordes a la funcionalidad del mercado laboral.

2. Atender los contenidos prácticos antes que los teóricos, y proporcionar una educación que responda a los requerimientos del saber hacer.

3. Fomentar el aprendizaje de tipo constructivista centralizado en el alumno, y desarrollar habilidades y destrezas en la solución de problemas.

En otras palabras, el mundo globalizado (semiglobalizado) requiere de profesionales de la información que aborden los problemas y los resuelvan; bibliotecólogos formados en esquemas de educación integral que ayuden al desarrollo de la sociedad siguiendo ante todo el camino de la especialidad, porque el conocimiento no tiene límites y mucho menos la proyección profesional que se pueda lograr sabiendo y aprendiendo más y más. Es decir, que el paso siguiente del bibliotecólogo que egrese de su carrera universitaria, más allá de traba- 
Discusión

jar e incursionar en el ámbito laboral, será saber que la escuela no termina en la universidad sino que es justo ahí donde comienza el camino de la especialidad. La demanda del mercado laboral requiere personas con conocimientos globales, por un lado, pero también más especializados en temas específicos dado que el desarrollo del conocimiento en todas las ramas está alcanzando niveles mayores y que el beneficio de estudiar una carrera profesional humanista no sólo se debe reflejar en la persona que la estudia sino también en su comunidad y en su país. 


\section{Conclusiones}

$\mathrm{D}$

e acuerdo con los trabajos presentados por algunos de los miembros del Seminario así como las participaciones, se entiende por flexibilidad curricular al proceso interno y externo que lleva al plan de estudios a ser congruente entre sus componentes y la compleja sociedad en la que nos encontramos insertos. Los avances que ha tenido el Espacio Europeo de Educación Superior en cuanto a Biblioteconomía y Documentación se ve reflejado en el Libro Blanco, en el que esa comunidad ha vertido sus acuerdos para formar un currículo único, deshaciendo intereses personales, institucionales y hasta nacionales y obedeciendo al claro objetivo de formar profesionales integrales que respondan a un mercado común. El ejemplo es bueno y el resultado mejor, pero a nivel de América Latina, el problema son las diferencias de un país a otro, tanto económicas como políticas, culturales y educativas, pues responden a realidades distintas y por tanto a distintos mercados; y además muchas instituciones bibliotecarias carecen de medios tecnológi- 
Flexibilidad curricular en la educación bibliotecológica

cos, pero aun las que cuentan con tecnología de punta y los recursos económicos suficientes para mantener esa infraestructura, tienen que darle respuesta a su sociedad con planes de estudio bibliotecológicos flexibles. A nivel institucional, de alguna forma los planes de estudio del área bibliotecológica han respondido a sus propias necesidades y entornos sociales; pero ahora requerimos de profesionales que respondan en el ámbito internacional con conocimientos y habilidades que sean válidos en cualquier parte del mundo y los ayuden a desempeñarse con la calidad que la sociedad espera de ellos. Estamos concientes de que los planes de estudio han intentado cierta flexibilidad promoviendo la incorporación de asignaturas optativas, culturales o científicas, pero se trata de trabajos individuales, esfuerzos aislados de cada institución, lo que hace que cada IES cuente con niveles educativos, títulos, perfiles, mapas curriculares, modelos educativos y estrategias de enseñanza y de aprendizaje distintos. Claro que al mismo tiempo también hay coincidencias que nos llevan a tener un mercado común y estas coincidencias nos llevan a pensar con optimismo que podemos y debemos trabajar en un currículo flexible. 
Por último, se enlistan algunas de la tareas pendientes en este tránsito curricular:

a) El establecimiento del perfil de profesional que se requiere formar.

b) La selección del método o corriente educativa que sustentará el proyecto curricular.

c) El establecimiento de un tronco común para los estudios de bibliotecología: ¿son Ciencias Sociales? ¿son Humanidades? ¿en dónde hemos de encuadrarlos?

d) El desarrollo de estrategias de enseñanza y de aprendizaje para este nuevo modelo educativo.

e) En cuanto a los docentes: formarlos de acuerdo con lo que demanda la sociedad global. Para lo cual incluso debemos olvidar parte de lo que hemos enseñado, y mostrarles que la tecnología nos ayuda a conseguir más información y aumenta el conocimiento y el intercambio de experiencias.

Estas actividades darán la pauta para futuros trabajos de análisis. 
Flexibilidad curricular en la Educación Bibliotecológica. La edición consta de 150 ejemplares. Coordinación editorial, Zindy E. Rodríguez Tamayo. Formación editorial, Carlos Ceballos Sosa. Revisión especializada, Francisco X. González y Ortíz. Centro Universitario de Investigaciones Bibliotecológicas/UNAM. Fue impreso en papel cultural ahuesado de 90 gr. en Grupo Edición S. A. de C. V., ubicado en Xochicalco 619, Col. Vertiz Narvarte, México D. F. Se terminó de imprimir en el mes de junio de 2008. 